OPEN ACCESS

Edited by:

Simona Rapposelli,

University of Pisa, Italy

Reviewed by:

Ruiwen Zhang,

University of Houston, United States

Simona Daniele,

University of Pisa, Italy

${ }^{*}$ Correspondence:

Jinyi Lang

langjy610@163.com

Chuan Xu

xuchuan100@163.com

${ }^{\dagger}$ These authors have contributed

equally to this work

Specialty section:

This article was submitted to Pharmacology of Anti-Cancer Drugs, a section of the journal

Frontiers in Pharmacology

Received: 24 February 2020 Accepted: 21 April 2020

Published: 07 May 2020

Citation:

Li W, Peng X, Lang J and Xu C (2020) Targeting

Mouse Double Minute 2: Current Concepts in DNA Damage Repair and Therapeutic Approaches in Cancer.

Front. Pharmacol. 11:631.

doi: 10.3389/fphar.2020.00631

\section{Targeting Mouse Double Minute 2: Current Concepts in DNA Damage Repair and Therapeutic Approaches in Cancer}

\author{
Wen $\mathrm{Li}^{1 \dagger}$, Xinhao Peng ${ }^{1,2 \dagger}$, Jinyi Lang ${ }^{1,2 *}$ and Chuan $\mathrm{Xu}^{1 *}$ \\ ${ }^{1}$ Cancer Clinical Research Center \& Integrative Cancer Center, Sichuan Cancer Hospital \& Institute Sichuan Cancer Center, \\ School of Medicine, University of Electronic Science and Technology of China, Chengdu, China, ${ }^{2}$ Radiation Oncology Key \\ Laboratory of Sichuan Province, Sichuan Cancer Hospital \& Institute Sichuan Cancer Center, School of Medicine, University \\ of Electronic Science and Technology of China, Chengdu, China
}

Defects in DNA damage repair may cause genome instability and cancer development. The tumor suppressor gene p53 regulates cell cycle arrest to allow time for DNA repair. The oncoprotein mouse double minute 2 (MDM2) promotes cell survival, proliferation, invasion, and therapeutic resistance in many types of cancer. The major role of MDM2 is to inhibit p53 activity and promote its degradation. In this review, we describe the influence of MDM2 on genomic instability, the role of MDM2 on releasing p53 and binding DNA repair proteins to inhibit repair, and the regulation network of MDM2 including its transcriptional modifications, protein stability, and localization following DNA damage in genome integrity maintenance and in MDM2-p53 axis control. We also discuss p53-dependent and p53 independent oncogenic function of MDM2 and the outcomes of clinical trials that have been used with clinical inhibitors targeting p53-MDM2 to treat certain cancers.

Keywords: MDM2, P53, DNA damage repair, genomic instability, clinical inhibitor

\section{INTRODUCTION}

Genomic instability is a hallmark of cancer and is regulated by a balance between DNA damage and repair (Aguilera and Garcia-Muse, 2013). The consequences of genomic instability include errorprone DNA synthesis, chromosome copy number variations and chromosomal structural aberrations (Jasin, 2000; Ganem et al., 2007) (Figure 1). Conversely, unrepaired damage may cause transcription and replication arrest, inducing cell death and senescence (Hoeijmakers, 2009).

In order to address the threat posed by genome changes, cells have evolved a kinase cascade signal transduction pathway called DNA damage response (DDR) (Harper and Elledge, 2007). The initial step in active DDR is a rapid accumulation of DNA repair proteins to damage sites, which serve as a scaffold to recruit downstream factors (Soutoglou and Misteli, 2010). Mis-regulated DDR may increase accumulation of unrepaired DNA lesions and trigger aberrant cell proliferation, leading to malignance diseases (Jackson and Bartek, 2009).

Tumor suppressor p53 accumulates at DNA damage sites directly in both sequence-specific and non-sequence-specific manner to play a protective role in DDR (Lee et al., 1995; Liu and KuleszMartin, 2001) (Figure 1). P53 deficiency leads to reduced repair activity and decreased cell survival 


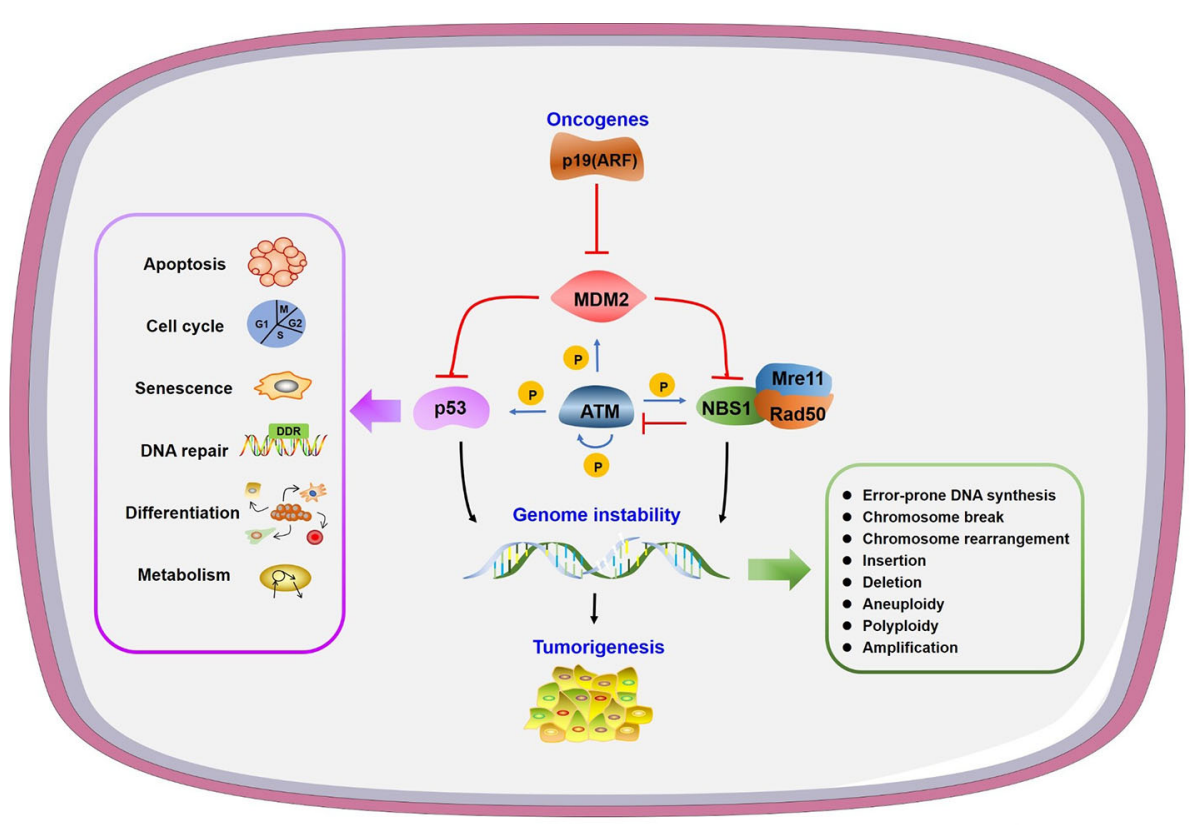

FIGURE 1 | Genome instability and other consequences caused by mouse double minute 2 (MDM2). Oncogene p19 (ARF) interacts with MDM2 to prevent its function. MDM2 can inhibit both p53 and NBS1 to regulate many physiological processes or/and lead to genome instability, in which ATM plays a central phosphorylation regulatory role.

after UV-induced DNA damage, indicating the participation of p53 in nucleotide excision repair (NER) (Smith et al., 1995). P53 also takes part in both global genome NER and transcription coupled NER through DNA polymerase $\delta$ and $\epsilon$, respectively (Mirzayans et al., 1996). Interaction between p53 with apyrimidinic endonuclease APE1/Ref-1 and the regulatory function of OGG1, MUTYH, and 3-methyladenine DNA glycosylase by $\mathrm{p} 53$ all indicate the function of p53 in base excision repair (BER). Among the two major pathways in double-strand break repair (DSBR), p53 interacts with both non-homologous end-joining (NHEJ) proteins and the promoter of homologous recombination (HR) protein RAD51 to regulate its expression (Williams and Schumacher, 2016).

The E3 ligase MDM2 (murine double minute 2) contains 491 amino acids and is a major negative regulator of p53 (Figure 1). MDM2 controls activity, subcellular localization, and stability of p53 (Eischen and Lozano, 2014). Increased MDM2 expression is commonly observed in different types of cancers, indicating its oncogenic function (Eischen and Lozano, 2014). MDM2 interacts with large and diverse substrates through complex structures, post-translational modifications, and diverse isoforms to function as a significant hub in different signal pathways (Fahraeus and Olivares-Illana, 2014). The major role of p53 as a tumor suppressor relies on its transcriptional activity to regulate target genes in diverse biological pathways (Sullivan et al., 2018). MDM2 binds p53 directly through N-terminal transactivation domain to inhibit p53 transactivation (Momand et al., 1992; Oliner et al., 1993). MDM2 also forms homodimers to ubiquitinate p53 leading to p53 proteasomal degradation (Haupt et al., 1997; Kubbutat et al., 1997). In this review, we highlight the specific regulation network of MDM2 in DDR and discuss the potential clinical applications of MDM2 antagonists and the perspective of developing novel combination strategies.

\section{GENOME INSTABILITY INDUCED BY MDM2}

As the negative regulator of $\mathrm{p} 53$, MDM2's function in cell survival versus cell death is complex and depends on the extent of DNA damage and the capacity of repair. The abnormal MDM2-p53 regulatory loop and its corresponding delayed DDR provide an additional layer for genomic instability control. The interaction of MDM2 with p53 and Mre11-Rad50Nbs1 complex indicates MDM2 affects genomic instability in both p53-dependent and p53-independent manner.

\section{MDM2 Affects Genomic Instability in p53-Dependent Manner}

Given that MDM2 binds with p53 to inhibit its transactivation and that it induces $\mathrm{p} 53$ protein degradation, it is reasonable to assume that MDM2 regulates genome instability through p53 directly. Oncogene Myc activates p19 (ARF)-MDM2 pathway to coordinate p53-dependent checkpoint and apoptotic program (Zindy et al., 1998; Eischen et al., 1999). ARF interacts with MDM2 to guide its degradation and prevents negative feedback 
of p53/MDM2, thus preventing p53 degradation (Zhang et al., 1998; Weber et al., 1999). A high level of MDM2 was identified in advanced stage breast ductal carcinomas and squamous cell carcinomas with wild-type p53. Overexpression of MDM2, and/or p53 deletion or mutation induced centrosome hyperamplification and chromosome instability in these cancer cells (Carroll et al., 1999). A study of lymphoma transformation showed that MDM2 overexpression in B cells led to a reduced susceptibility to p53-dependent apoptosis through inhibition of p53 and p21 (Wang et al., 2008). MDM2 transgenic mice also showed increased chromosome breaks, chromosome fusions, aneuploidy, and polyploidy (Lushnikova et al., 2011). It has also been shown that p53 disruption by MDM2 overexpression activates the intra S-phase checkpoint to inhibit DNA replication origin firing, causing replication fork instability (Frum et al., 2014; Primo and Teixeira, 2019).

\section{MDM2 Affects Genomic Instability in p53-Independent Manner}

MDM2 also affects genomic instability independent of p53. It was found that mammary epithelial cells underwent multiple rounds of $S$ phase without cell division to form increased polyploidy in response to MDM2 overexpression regardless of p53 expression level in mice (Lundgren et al., 1997). Mre11/ Rad50/NBS1 (MRN) complex is a central sensor in DSBR. Mre11 and NBS1 mutant mice exhibit checkpoint defects and chromosomal instability (Stracker et al., 2004). MDM2 associates with MRN complex through the direct interaction with NBS1 independent of p53, thus leads to recruitment of MDM2 at DNA damage sites with delayed DNA repair and compromised DNA integrity (Alt et al., 2005). Interaction of MDM2 with NBS1 inhibits DNA repair and leads to increased chromosome breaks and transformation efficiency in p53 deficient cells (Bouska et al., 2008). With small molecular inhibitors targeting the interaction of p53 with MDM2, a p53 independent function of MDM2 in NBS1 regulation is found and worthy of considering in cancer drug design (Bouska and Eischen, 2009). In addition to binds NBS1, it has been reported that MDM2 ubiquitinates transcription factor HBP1 to facilitate its degradation, thus preventing the transcriptional inhibition role of HBP1 to its target genes to induce genomic instability like global DNA hypermethylation and histone hypermethylation (Cao et al., 2019).

\section{INHIBITORY ROLE OF MDM2 IN DNA REPAIR}

MDM2 is regulated downstream of DNA damage by several mechanisms such as inactivation by post-translational modification and destruction p53-MDM2 interaction to relieve p53 inhibition. Increased p53 level leads to cell senescence, cell cycle arrest, and apoptosis. In the meanwhile, the interaction of MDM2 with DNA repair complex MRN exists and is independent of p53 state (Eischen, 2017). The accumulated unrepaired DNA breaks further activate p53 and facilitate alterations such as chromosome translocations, gene fusions, increased micronuclei, and gene amplification, which are common causes of cancer malignancy (Morgan et al., 1998; Bunting and Nussenzweig, 2013). MDM2 is in turn transcriptionally regulated by p53 to form a feed-back loop to maintain cellular homeostasis under genetic stress.

\section{Release of p53 After DNA Damage}

The regulatory function of MDM2 on p53 after DNA damage is complex as it depends on the type of damage, p53 substrates, and various modifications on $\mathrm{p} 53$ and MDM2 proteins. The key step of p53 activation after DNA damage and other genetic stress results in the disruption of p53-MDM2 interaction and p53 release (Figure 2). The inhibitory role of MDM2 on p53 includes blocking p53 transcriptional activation and regulating p53 protein level. Disruption of p53-MDM2 interaction alone is enough for p53 stabilization and activation even without DNA damage (Bottger et al., 1997). The MDM2 binding sites in p53 amino terminus overlap with the binding sites in p53 that interact with the transcription machinery. MDM2 competes with transcription factors such as TFIID and TAFII31 for p53 binding to block p53 mediated transcription (Lin et al., 1994; Lu and Levine, 1995; Thut et al., 1995). A study also indicated that MDM2 directly repressed basal transcriptional machinery through its inhibitory domain (Thut et al., 1997). NEDD8 has a similar modification with ubiquitination, which can conjugate with p53 in a MDM2 dependent manner to repress p53 transcription (Xirodimas et al., 2004). MDM2 also leads to a proteasomal degradation of p53. Moreover, expression of MDM2 significantly inhibits p53 accumulation after DNA damage. These results indicate a post-translational regulation under stress conditions (Haupt et al., 1997; Kubbutat et al., 1997).

Treatment with DNA damaging agents induce p53 phosphorylation at serine 15 and 37 which causes conformation changes in $\mathrm{p} 53$, resulting in reduced interaction of p53 with MDM2 (Shieh et al., 1997). P53 acetylation was also reported to block p53-MDM2 interaction and which enable p53dependent cell growth arrest and apoptosis under stress conditions (Tang et al., 2008). In addition, cells exhibit increased p53 phosphorylation by ATM, ATR, and other kinases after DNA damage with UV light and other agents, leading to p53 stabilization and enhanced DNA binding. The higher levels of p53 further activate transcription of downstream targets including MDM2 (Kruse and Gu, 2009). As the repair process progresses, increased MDM2 decreases p53 expression and activity through the above mechanisms, forming a regulatory feedback loop to keep p53 and MDM2 protein at a basal level (Maltzman and Czyzyk, 1984; Freedman et al., 1999). The consequences of p53 regulation by MDM2 also depend on MDM2 activity. Low levels of MDM2 activity lead to p53 monoubiquitination and nuclear export whereas high levels promote p53 polyubiquitination and nuclear degradation (Li et al., 2003).

\section{Interaction of MDM2 With MRN Complex}

Mre11/Rad50/Nbs1 (MRN) complex is essential in the maintenance of genome, meiosis, and telomere (D'Amours and 


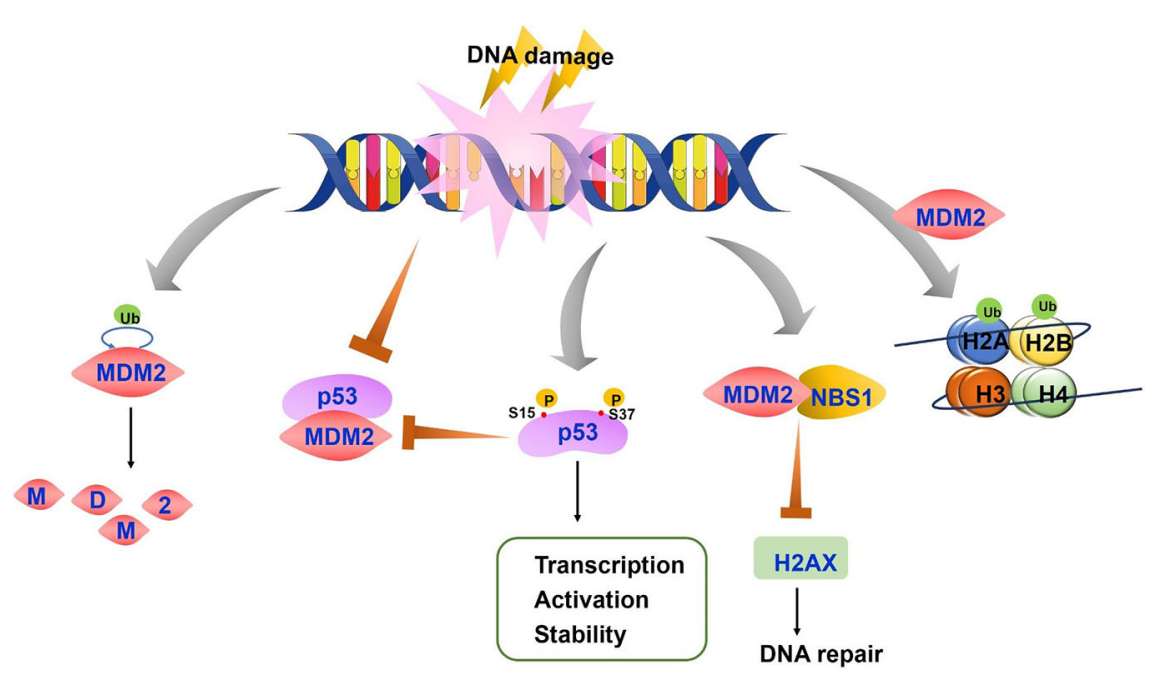

FIGURE 2 | The regulation of p53-mouse double minute 2 (MDM2) axis after DNA damage. On the condition of DNA damage, both MDM2 auto-degradation and the disruption of p53-MDM2 interaction lead to stable and active p53. P53 is also phosphorylated at Ser15 and Ser37, resulting in the reduced p53-MDM2 interaction and increased transcription, activation and stability of p53 protein. MDM2-NBS1 association delays H2AX phosphorylation and inhibits DNA repair. MDM2 induces histones $\mathrm{H} 2 \mathrm{~A}$ and $\mathrm{H} 2 \mathrm{~B}$ monoubiquitylation, which affects chromatin structure and accessibility.

Jackson, 2002). Mre11 exhibits $3^{\prime}-5^{\prime}$ double strand DNA exonuclease and endonuclease activity and joints two broken ends using their microhomology domains (Paull and Gellert, 1999). Rad50 is a structural maintenance of chromosome (SMC) related protein, which functions in bridging DSB ends together to facilitate Mre11-dependent DSB end processing (Williams et al., 2007). NBS1 recognizes DSB ends and transduces cell cycle checkpoint signals through ATM-induced epigenetic modification. NBS1 also functions in chromosome remodeling in response to DSB (Williams et al., 2007). After ATM activation and HR repair initiation by MRN, nucleases such as CtIP, Exo1, and Dna2/BLM, cause DSB end resection to form 3'-overhangs, which are coated by RPA and Rad51 to facilitate strand exchange (Mladenov et al., 2016).

Although MDM2 promotes genomic instability and cancer development through the inhibition of $\mathrm{p} 53$, studies have also identified MDM2 function independent of p53 (Bouska and Eischen, 2009). MDM2 directly interacts with NBS1 through a 31-amino-acid region and is recruited to damage sites independent of p53 and ARF, a negative regulator of MDM2 (Alt et al., 2005) (Figure 2). MDM2-NBS1 association delays H2AX and ATM-S/TQ phosphorylation and inhibits DNA repair (Bouska et al., 2008). Additionally, MDM2 can bind other proteins involved in DNA replication or repair, such as DNA polymerase $\epsilon$ (Asahara et al., 2003).

\section{Other Regulatory Mechanisms of MDM2 Following DNA Damage}

Mice with a hypomorphic allele in MDM2 gene revealed increased p53 transcriptional activation and apoptosis (Mendrysa et al., 2003). Increased MDM2 protein level as a result of a single nucleotide polymorphism led to a decreased p53 signal transduction and higher tumor risk (Bond et al., 2004). All these evidences indicate that the amount of MDM2 protein dictates the physiological consequences of p53 activation. Further studies found that DNA damage induced MDM2 autodegradation, which conversely stabilized and activated p53 (Stommel and Wahl, 2004). The half-life of MDM2 decreased after treatment with DNA damage agents neocarzinostatin (NCS), UV irradiation, and BCNU, while p53 stability and activation increased. This process is reversible and the half-life of MDM2 increases which corrects with unstable and inactive p53 when stress was eliminated (Stommel and Wahl, 2005).

Other studies demonstrated that MDM2 modulate DDR process through its association with and modification of chromatin, especially the promoter region of p53 target genes. Histone modification has long been known to affect transcription and DNA repair by influencing chromatin structure and accessibility, which is important for the recruitment of chromatin remodeling factors. MDM2 had been reported to interact with histones directly and induce monoubiquitylation of histones $\mathrm{H} 2 \mathrm{~A}$ and $\mathrm{H} 2 \mathrm{~B}$ in vitro and of $\mathrm{H} 2 \mathrm{~B}$ in vivo (Minsky and Oren, 2004). In addition to that, the p53-MDM2 interaction may change p53 conformation and inhibit its binding to DNA. This function of MDM2 is mediated by its central acidic domain which binds to histone methyl transferase Suv39h1. The Suv39h1-MDM2 interaction restores p53 conformation allowing DNA binding of p53-MDM2-Suv39h1 complex (Cross et al., 2011). On the contrary, MDM2 was also reported to polyubiquitinate Suv39h1 at lysine 87 and to promote its degradation (Bosch-Presegue et al., 2011). This could be attributed to differences in cell context and experimental 
conditions (Wienken et al., 2017). A p53-independent function of MDM2 in gene repression under stress conditions through chromatin modification warrants further investigation.

\section{MDM2 REGULATION IN RESPONSE TO DNA DAMAGE}

MDM2 binds $\mathrm{N}$ terminal of $\mathrm{p} 53$ to inhibit its transcription and promote its proteasomal degradation. MDM2 is also regulated by p53 to form an autoregulatory loop. Since MDM2 gene amplification and protein overexpression are found widely in human cancers, investigating the MDM2 related regulatory network under DNA damage is essential to understand its biological function as an oncogene and to identify novel targets for cancer therapy.

\section{Regulation of MDM2 Expression}

MDM2 gene can be transcribed from two independent promoters, P1 and P2. The P1 promoter transcribes from the first exon but without exon 2. P1 promoter carries out basal transcription and its activation does not need $\mathrm{p} 53$. P2 promoter is located within the first intron which includes two p53-binding sites and the transcriptional activation of P2 depends on p53 (Barak et al., 1994; Zauberman et al., 1995). Since the identification of increased expression of MDM2 variant in a range of human cancers and decreased expression in normal tissue in 1996, more than 72 kinds of MDM2 splice variants have been observed in both cancer and normal cells (Sigalas et al., 1996; Rosso et al., 2014). Some of these variants are specifically spliced in response to DNA damage (Jeyaraj et al., 2009). However, their molecular mechanisms remain unknown.

The most common splice variants of MDM2 are MDM2-A (ALT2), MDM2-B (ALT1), and MDM2-C (ALT3). Compared to the full length MDM2 (MDM2-FL), which consists of 12 exons, MDM2-A lacks exon 4-9, MDM2-B lacks exon 4-11, and MDM2-C lacks exon 5-9. All these three variants lack p53 binding site at $\mathrm{N}$ terminal while they retain the $\mathrm{C}$ terminal RING domain, which facilitates their interaction with MDM2-FL (Huun et al., 2017). Based on such structural features, MDM2-A has been characterized to be a p53 activator. MDM2-A expression exhibits enhanced p53 activity and decreased transformation in p53-null setting (Volk et al., 2009). Activated p53/p21 pathway and increased cyclins D1 and E were discovered after MDM2-A expression (Sanchez-Aguilera et al., 2006). MDM2-B is frequently expressed in various cancer types including ovarian cancer, bladder cancer, astrocytic cancer, breast cancer, and giant cell tumors of bone (Sigalas et al., 1996; Matsumoto et al., 1998; Evdokiou et al., 2001; Lukas et al., 2001). MDM2-B binds and sequesters full-length MDM2 in the cytoplasm and promotes p53 transcription by inhibiting interaction of MDM2-FL with p53 (Evans et al., 2001). Using a specific human MDM2-C antibody, high expression of endogenous MDM2-C was detected in cancer cell lines and in cancer tissues. Unlike MDM2-A and MDM2-B, MDM2-C had no effect on p53 degradation and transcription regulation but showed p53-independent transformation property (Okoro et al., 2013).

Studies have identified a single nucleotide polymorphism (T/ G SNP309) in MDM2 promoter region. This variant exhibit increased affinity toward the transcriptional activator Sp1, resulting in higher levels of MDM2 RNA and protein (Bond et al., 2004). In MDM2 SNP309 cells, p53 binds chromatin but cannot be activated (Arva et al., 2005). Overexpressed MDM2 with SNP309 is associated with increased risk of renal cancer development and worse patient prognosis in esophageal squamous cell carcinoma and B-cell chronic lymphocytic leukemia (Hong et al., 2005; Hirata et al., 2007; Gryshchenko et al., 2008). MDM2 expression can be regulated by miRNAs induced by $\mathrm{p} 53$. Wild type p53 was identified in many multiple myeloma cases which induced the expression of miR-192, 215, and 194 leading to the downregulation of MDM2 (Pichiorri et al., 2010).

\section{Regulation of MDM2 Modification}

The structural domains of MDM2 include (1) an N terminal lid domain (25-100 aa), a hydrophobic pocket controlling p53 binding, (2) a nuclear localization site (179-185 aa, NLS), (3) a nuclear export site (190-202 aa, NES), (4) a central acidic domain (243-301 aa), (5) a zinc finger domain (290-335 aa), and (6) a RING domain (432-491 aa), which is in charge of E3 ligase activity (Fahraeus and Olivares-Illana, 2014) (Figure 3). MDM2 can be modified multisite phosphorylation/ dephosphorylation, ubiquitination and SUMOylating (Figure 3).

\section{Phosphorylation}

MDM2 is frequently phosphorylated especially in the central acidic domain (Blattner et al., 2002). Many kinases are reported to regulate MDM2 phosphorylation which controls its downstream activation or inhibition. The multiple phosphorylation sites within MDM2 can be divided into three groups (1) serine residues at 157, 166, 186, and 188 all of which are present near nuclear localization sites and nuclear export sites, (2) serine residues at 240,242, 246, 253, 256, 260, 262, and 269 which is the phosphorylated cluster in the absence of any stress, and (3) serine 17, threonine 216, tyrosine 276, tyrosine 394, and serine at 395 and 407, all of which are phosphorylated under DNA damage stimulation (Meek and Hupp, 2010).

The most important mediators in DDR are phosphatidylinositol 3-kinase-like protein kinase (PIKKs) family like ATM (ataxia telangiectasia mutated), ATR (ATM and Rad3-related), and DNA-PK (DNA-dependent protein kinase). DNA double strand breaks activate ATM and DNA-PK to induce downstream transduction. ATR is activated by the recruitment of RPAcoated single strand breaks with a partner protein ATRIP (Ciccia and Elledge, 2010). Based on the presence of serine and threonine residues, which make up about $20 \%$ of all amino acids in MDM2 protein, MDM2 is a suitable phosphorylation substrate (Meek and Knippschild, 2003). The posttranslational modification of N-terminal region in both MDM2 and p53 can disrupt their interaction under cellular stress (Appella and Anderson, 2001). The 16-24 residues of MDM2 were reported to form a lid crossing over p53 binding sites. This region 

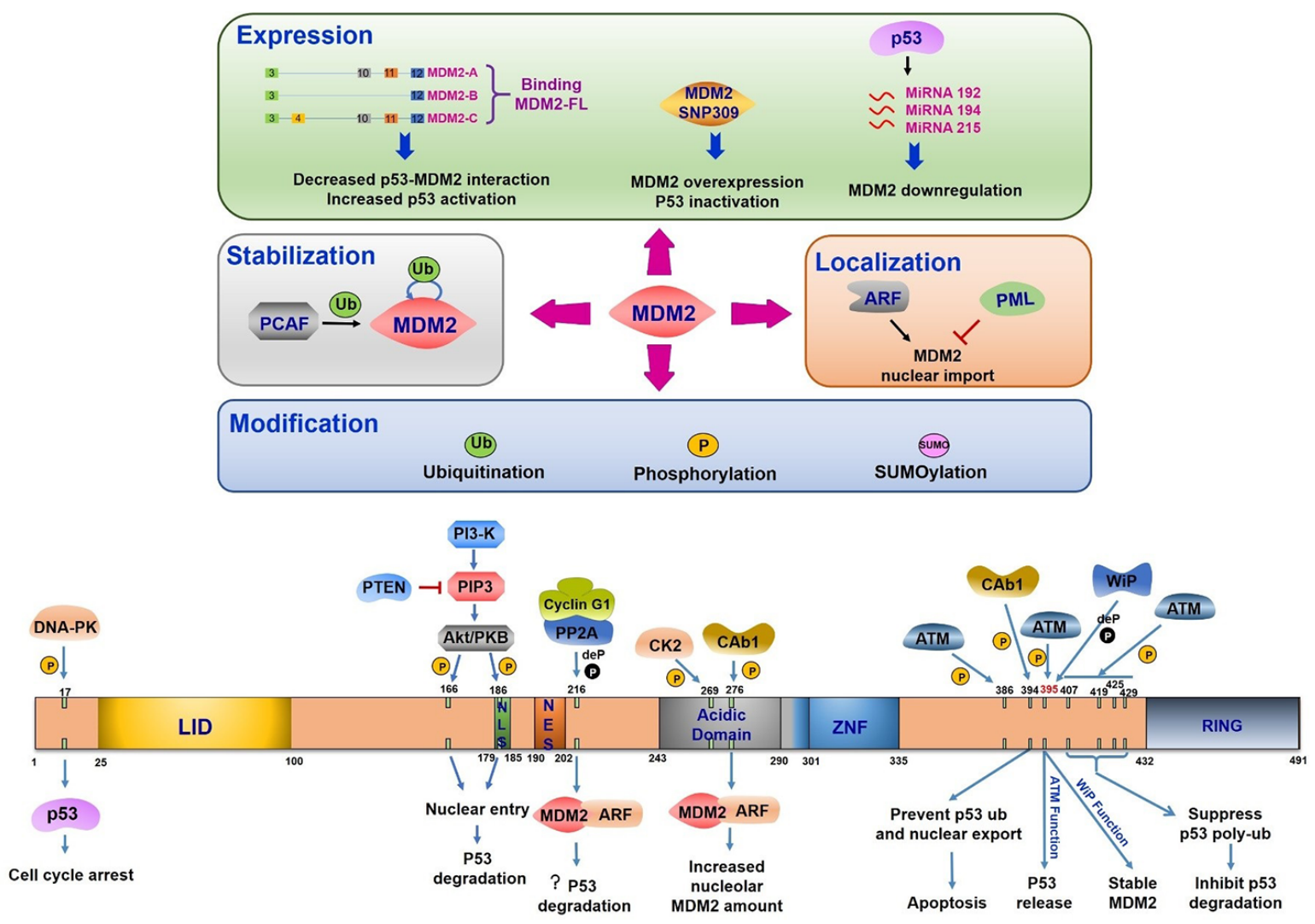

FIGURE 3 | Mouse double minute 2 (MDM2) regulation under DNA damage. The upper half part reflects the regulation of MDM2 expression, stabilization,

modification, and location. All the three splice variants can interact with MDM2-FL, leading to the disruption of p53-MDM2 interaction and increased p53 activation. The single nucleotide polymorphism (T/G SNP309) exhibits increased MDM2 expression and p53 inhibition. P53 induces miR-192, 215, and 194 expression, which leads to MDM2 downregulation. The PCAF induced ubiquitination or auto-ubiquitination in MDM2 relate to its stability. ARF-induced MDM2 nucleus importation increases MDM2 mediated p53 response. PML plays the opposite role. MDM2 modification includes its ubiquitination, phosphorylation, and SUMOylation. The bottom half part indicates domains of MDM2, its phosphorylation and dephosphorylation sites, the related kinases or phosphatases, and the corresponding consequences. LID, Lid domain; NLS, nuclear localization site; NES, nuclear export site; Acidic Domain, central acidic domain; ZNF, zinc finger domain; RING, RING domain; ? (question mark), this function is still needed to be confirmed.

functions in stabilizing MDM2 protein but weakly inhibits p53 binding (McCoy et al., 2003). Interestingly, phosphorylated states in this region showed a significant influence in disrupting MDM2-p53 interaction. Following DNA damage, DNA-PK phosphorylates MDM2 at serine 17 and inhibits its interaction with p53, leading to p53 activation and G1 cell cycle arrest (Mayo et al., 1997). ATM mediated substrate phosphorylation is an early response to DNA damage. MDM2 is phosphorylated by ATM at serine 395 (serine 394 in mouse) facilitating p53 release and accumulation in response to ionizing radiation and radiomimetic agents but not to UV radiation (de Toledo et al., 2000; Maya et al., 2001). Other residues (Ser386, Ser395, Ser407, Thr419, Ser425, and Ser429) located in C terminals of MDM2 have been identified to be phosphorylated by ATM after DNA damage in a redundant manner (Cheng et al., 2009). The phosphorylation of these sites inhibits oligomerization of RING domain resulting in suppression of p53 poly-ubiquitination and degradation (Cheng et al., 2011). Activation of a nuclear tyrosine kinase $\mathrm{c}-\mathrm{Abl}$ is another response to ionizing radiation. This kinase is phosphorylated by ATM and is involved in cell cycle control (Baskaran et al., 1997; Brown and McCarthy, 1997; Shafman et al., 1997). Following DNA damage, c-Abl binds MDM2 directly, phosphorylates MDM2 at tyrosine 394, and prevents p53 ubiquitination and its nuclear export. This c-Abl induced MDM2 tyrosine 394 phosphorylation triggered increased p53 transcription and decreased degradation leading to p53-mediated apoptosis (Sionov et al., 2001; Goldberg et al., 2002). Additionally, tyrosine 276 was found to be phosphorylated by c-Abl in response to DNA damage in vitro. This modification enhanced MDM2 interaction with ARF with an increased expression of nucleolar MDM2 (Dias et al., 2006). These striking observations pointed out that c-Abl phosphorylation site is adjacent to ATM phosphorylation site indicating that ATM regulates MDM2 phosphorylation both in direct and indirect manner.

Recent studies indicate that many growth factors and cytokines are involved in cancer progression by regulating cell proliferation and apoptosis. The serine/threonine protein kinase 
Akt/PKB is an essential signal transducer downstream of phosphatidylinositol 3-kinase (PI3-kinase) (Lawlor and Alessi, 2001). MDM2 can be phosphorylated at serine 166 and serine 186 by Akt/PKB which results nuclear translocation from cytoplasm (Mayo and Donner, 2001). In addition to that, HER-2/neu-mediated Akt activation phosphorylates MDM2 to enhance p300 interaction and inhibits p19ARF interaction, resulting in increased degradation of p53 and blocked cytotoxic effect of DNA damage agents in cancer cells (Zhou et al., 2001). Following stimulation with growth factors, PI3-kinase is activated and generates second messenger phosphatidylinositol (3,4,5)-trisphosphate PIP3 (Vanhaesebroeck and Alessi, 2000). A lipid phosphatase and tumor suppressor protein PTEN dephosphorylates PIP3 to disrupt this signal transduction. The mechanism is illustrated by the fact that high level of PTEN or PI3-K inhibitor dephosphorylates serine 166 and serine 186 of MDM2 and blocks its nuclear entry leading to an increased cellular p53 level and activity. Meanwhile, p53 further promotes PTEN expression to form a positive feedback loop in response to cellular stress. The PI3-K-Akt-MDM2 axis connects two important tumor suppressor PTEN and p53 to regulate cell survival, drug resistance and tumorigenesis (Mayo and Donner, 2001; Mayo et al., 2002; Mayo and Donner, 2002; Ogawara et al., 2002). The protein kinase CK2 (CK2) is required for cell viability and cell cycle progression. CK2 is another protein kinase that phosphorylates MDM2 at serine 269 (Gotz et al., 1999; Hjerrild et al., 2001). The investigation of other kinases targeting MDM2 may further shed light on MDM2-p53 function.

It is equally important to consider MDM2 dephosphorylation mechanisms and impact on $\mathrm{p} 53$ regulation under cellular stress. Wild type p53-induced phosphatase 1 (Wip/PPM1D) can dephosphorylate MDM2 at serine 395, the same site that is phosphorylated by ATM, to inhibit MDM2 autophosphorylation and to stabilize MDM2 protein (Lu et al., 2007). Activation of p53 induces cyclin G1 transcription after DNA damage. Cyclin G1 interacts with a subunit of protein phosphatase 2A subunit (PP2A) to dephosphorylate MDM2 at tyrosine 216 site, promoting the ARF/MDM2 complex formation and p53 degradation (Kimura and Nojima, 2002; Meek and Knippschild, 2003). In another study, Cyclin G1/PP2A dephosphorylated MDM2 at both tyrosine 216 and serine 166 to activate it and to negatively regulate p53. However, the downstream functions of cyclin G1-p53 are complicated under various cellular stress. Exploring these issues should lead to a further understanding of p53-MDM2 regulation network (Okamoto et al., 2002).

\section{Ubiquitination}

During the ubiquitin conjugation modification process, the E3 ligase interacts specifically with target proteins to transfer ubiquitin. As a ubiquitin E3 ligase, MDM2 not only ubiquitinates p53 to guide its proteasomal degradation but also exhibits auto-ubiquitination function via $\mathrm{C}$ terminal RING finger domain (Fang et al., 2000; Honda and Yasuda, 2000). Multiple monoubiquitin sites exist in p53 which requires MDM2 isomerization (Lai et al., 2001). MDM2 auto-ubiquitination facilitates E2-conjugating enzymes accumulation and increased ubiquitination activity of MDM2 substrates, nevertheless the auto-ubiquitination is not required for MDM2 degradation (Itahana et al., 2007; Ranaweera and Yang, 2013). The choice between auto-ubiquitination and substrate-ubiquitination is regulated by other MDM2 posttranslational modifications including phosphorylation and SUMOylation (Meek and Knippschild, 2003). Other proteins are also found in the regulation of MDM2 ubiquitination. Transcription factor Yin Yang 1 (YY1) promotes p53 ubiquitination and degradation, which relays on enhanced p53-MDM2 interaction but not on its transcriptional activity (Sui et al., 2004).

\section{SUMOylation}

SUMO is a small ubiquitin-related modifier that modulates downstream gene expression in a ubiquitination-like pathway to influence protein stability, localization, DNA binding, and activation (Gill, 2003). Sumo conjugating enzyme Ubc9 mediated SUMOylation shows different consequences according to its substrates and the type of DNA damage. Residues 40-59 on MDM2 are responsible for Ubc9-MDM2 interaction and MDM2 SUMOylation, which is decreased following UV treatment (Buschmann et al., 2001). In response to radiation, the SUMOylation of MDM2 decreased in a doseand time-dependent manner to enhance MDM2 autoubiquitination and to abrogate substrate-ubiquitination, resulting in increased p53 level (Buschmann et al., 2000). SUMOylation of MDM2 modulates MDM2 E3 ligase activity. SUMO-specific protease 2 (SENP2) removes SUMO modification from MDM2 and decrease p53 level (Chiu et al., 2008).

\section{Regulation of MDM2 Stabilization}

MDM2 exhibits auto-ubiquitination function to promote protein degradation by ubiquitin-proteasome pathway in response to cellular stress or DNA damage (Chang et al., 1998). The half-life of MDM2 is short and the ubiquitin-related regulation balance shifts to MDM2 auto-ubiquitination and degradation to relieve p53 inhibition after exposure to these stressors (Stommel and Wahl, 2004). The histone acetyltransferase (HAT) p300-CBPassociated factor (PCAF) was reported to control MDM2 stability and p53 function through its ubiquitination activity (Linares et al., 2007).

\section{Regulation of MDM2 Localization}

The structural property of MDM2 enables it to shuttle between the nucleus and the cytoplasm. Subcellular location of MDM2 is important for regulating p53 transcriptional activity and degradation. In addition to the nuclear entry regulated by MDM2 phosphorylation, MDM2 mediated p53 nuclear export is also required for $\mathrm{p} 53$ degradation. MDM2 overexpression promotes p53 cytoplasmic location and this function relies on the RING finger domain in MDM2 and the NES signal in p53 (Boyd et al., 2000; Geyer et al., 2000). By contrast, the export protein CRM1 mediated p53 nuclear export did not cause p53 
degradation indicating that the export of p53 is not essential for its degradation (Lohrum et al., 2001). The translocation of MDM2 into nucleus through ARF is needed for MDM2mediated p53 response (Weber et al., 1999). Another tumor suppressor promyelocytic leukemia (PML) interacts with MDM2 and promotes p53 activity by enhancing the accumulation of p53 at PML nuclear bodies (Wei et al., 2003). Following DNA damage, PML localizes at nucleoli and sequesters MDM2 nucleolar localization to increase p53 stability (Bernardi et al., 2004).

\section{MDM2 IN CANCER DEVELOPMENT}

The overexpression of MDM2 inhibits p53 activity. Highly expressed MDM2 attenuates p53 stress response and promotes cancer progression. Study in sarcomas identified MDM2 gene amplification together with a decreased growth control by p53 (Oliner et al., 1992). MDM2 overexpression was also found in head and neck squamous carcinomas, indicating its contribution in cancer development (Valentin-Vega et al., 2007). An efficient strategy would be to target MDM2 by improving p53 activity in some cancer types (Vazquez et al., 2008). Since MDM2 functions in p53 dependent and independent manner, studies of the roles of MDM2 in cancer development need to be considered in both situations.

\section{P53 Dependent Oncogenic Function of MDM2}

The most important oncogenic function of MDM2 comes from its binding with transcriptional activation domain and abrogating the antiproliferation effects of tumor suppressor protein p53 (Haupt et al., 1997). MDM2 SNP309 is associated with high risk of cancer development, largely because of increased MDM2 protein level and inhibition of p53 activation (Bond and Levine, 2007). As a common feature of solid tumors, the hypoxia microenvironment is important in tumor growth, progression and metastatic potential. Hypoxia was reported to induce MDM2 up-regulation leading to a decreased p53 function (Zhang and Hill, 2004). Alternative splice forms of MDM2 have been found in various human cancers, indicating diversified regulatory mode of MDM2 and its transcriptional variants (Jeyaraj et al., 2009). Both MDM2 overexpression and/or p53 mutation are exhibited in human cancers (Figure 4). Over half of human cancers showed deficient or mutant $\mathrm{p} 53$ protein whereas the remaining harbor other kinds of alterations like MDM2 overexpression (Senturk and Manfredi, 2012). Mice homozygous for p53 null allele developed spontaneous tumors with high probability, and most of the tumors were lymphomas (Donehower et al., 1992; Jacks et al., 1994; Purdie et al., 1994). MDM2 plays an essential role in $\mathrm{p} 53$ regulation in vivo. The evidence came from MDM2 single knockout and MDM2/p53 double knockout mice. It was found that MDM2 loss triggered

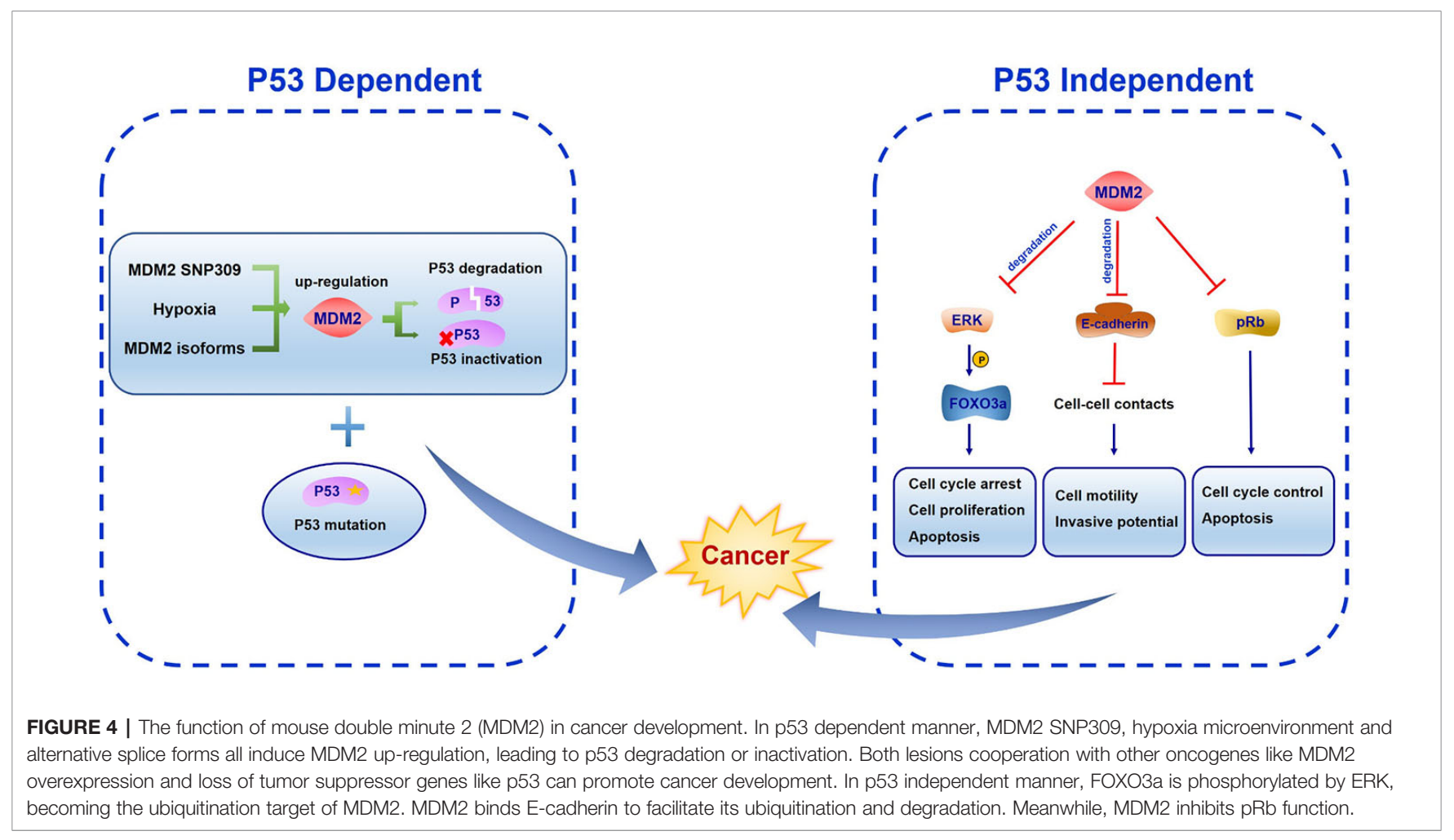


embryonic lethality in mice. In contrast, mice deficient in both MDM2 and p53 were rescued from this phenotype leading to normal development and survival. These results suggest the function of MDM2 in negative regulating p53 activity (Jones et al., 1995; Montes et al., 1995)

The oncogenic feature of MDM2 only manifests in a background of pre-existing genetic lesions in cell-based studies. Because on the short half-life of MDM2 and the toxic cellular response to MDM2 overexpression, it is difficult to increase MDM2 expression to induce p53 inactivity and trigger transformation or tumorigenesis (Wade et al., 2013). Both lesions cooperate with other oncogenes and loss of tumor suppressor genes can promote tumorigenesis (Wade et al., 2013).

\section{P53 Independent Oncogenic Function of MDM2}

The p53 independent oncogenic function of MDM2 was identified in MDM2 transgenic mice in which mammary gland were prone to spontaneous cancer formation both in the presence or absence of p53 (Lundgren et al., 1997; Jones et al., 1998). One of the underlying mechanisms of this effect may be the MDM2-NBS1 interaction which leads to inhibition of DNA repair and increased transformation efficiency (Bouska et al., 2008). Several MDM2 spliced variants have been found in different cancer types which are absent in normal tissues. All the variants can transform NIH3T3 cells. Moreover, some of them were unable to bind p53 but were still expressed in latestage and high-grade ovarian and bladder cancer, suggesting a p53-independent oncogenic function (Sigalas et al., 1996). Considering the E3 ligase activity of MDM2, it is reasonable to assume that MDM2 ubiquitinates other targets involved in proliferation and tumorigenesis. The RAS-RAF-MEK-ERKMAP kinase pathway is the most characterized signal transduction pathway regulating cell cycle arrest, cell proliferation, differentiation, and apoptosis. A wide range of mutations in these genes have been found in human cancers (Davies et al., 2002). ERK was reported to interact with and phosphorylate transcription factor FOXO3a at serine 294, 344, and 425. Phosphorylated FOXO3a is a ubiquitination target of MDM2 and is degraded by MDM2 mediated proteasome pathway in response to oncogenic growth factor signals (Yang et al., 2008). Southern blot and PCR methods have identified more frequent MDM2 gene amplification in metastatic or recurrent osteosarcomas than the corresponding primary cancer (Ladanyi et al., 1993). This can be attributed to Ecadherin, an epithelial-to-mesenchymal transition associated cell-adhesion protein which interacts with MDM2 to facilitate its ubiquitination and degradation (Yang et al., 2006). Paradoxically, Slug (SNAI2), which belongs to Snail transcriptional repressor family, can be downregulated by MDM2 to enhance E-cadherin expression and repress cancer invasiveness (Wang et al., 2009). In addition, enhanced MDM2 expression correlates with increased vascular endothelial growth factor (VEGF) expression which may facilitate vascularity, metastasis, and tumor growth (Takahashi et al., 1995; Zietz et al., 1998). Other than p53, another tumor suppressor gene retinoblastoma protein $(\mathrm{pRb})$ is frequently mutated in human cancers. MDM2 was identified to interact with $\mathrm{pRb}$ directly to inhibit its cell cycle and apoptosis regulatory function (Xiao et al., 1995).

\section{MDM2 AS A TARGET FOR CANCER THERAPY}

The regulation functions of MDM2 on p53 focus on ubiquitinating p53 through the E3 ligase activity, blocking the binding of $\mathrm{p} 53$ to its target transcription sites and exporting p53 from nucleus, all suggests the necessity to design inhibitors targeting the interaction sites between MDM2 and p53. Considering the deficiency of single target drugs in therapeutic effect maintenance over time as well as the conduciveness to activate alternative signaling pathways facilitating drug resistance, dual or multi-targeting MDM2 inhibitors are emerging. Here, we review inhibitors which have been successfully developed for the clinical trials (Table 1).

\section{Inhibitors Targeting MDM2-p53 in Clinical Trials}

Nutlins was a series of cis-imidazoline analogs identified to bind MDM2 in the p53-binding pocket, leading to cell cycle arrest and apoptosis in cancer cells, as well as growth inhibition of human tumor xenografts in nude mice (Vassilev et al., 2004). Several inhibitors targeting MDM2-p53 such as RG7112, RG7388, RG7775, SAR405838, HDM201, APG-115, AMG-232, and MK-8242 have recently been developed to treat human cancers with clinical trials. However, more clinical data is required to verify if these inhibitors can effectively block MDM2 or activate p53 and further improve the clinical efficacy in patients.

\section{RG7112}

RG7112 was the first small-molecule MDM2 inhibitor to enter human clinical trials and which was derived from structural modification of Nutlin-3a (Liu et al., 2019). RG7112 was designed to target MDM2 in p53-binding pocket (Vu et al., 2013) and restored p53 activity inducing robust p21 expression and apoptosis in p53 wild-type glioblastomas cell (Verreault et al., 2016). So far, seven clinical studies on RG7112 have been completed (http://www.clinicaltrials.gov/; NCT01677780, NCT01605526, NCT01143740, NCT01164033, NCT00559533, NCT00623870, NCT01677780). Study of NP25299 (NCT01164033) was an open-label, randomized, cross-over study in patients with solid tumors. It evaluated the effects of food on the pharmacokinetics of single oral doses of RG7112. This study included two parts: the first one comprised an initial single-dose, while the other comprised four different treatment schedules of increased doses. The results indicated that RG7112 was generally well tolerated with GI toxicities, the most common AEs, making it treatable with anti-emetics (Patnaik et al., 2015). 
TABLE 1 | Overview of small-molecules targeting mouse double minute 2 (MDM2) in clinical trials.

\begin{tabular}{|c|c|c|c|c|}
\hline Drug & Phases & NCT Number & Status & Conditions \\
\hline RG7211 & Phase 1 & NCT00559533 & Completed & Neoplasms \\
\hline RG7211 & Phase 1 & NCT00623870 & Completed & Hematologic neoplasms \\
\hline RG7211 & Phase 1 & NCT01143740 & Completed & Sarcoma \\
\hline RG7211 & Phase 1 & NCT01164033 & Completed & Neoplasms \\
\hline RG7211 & Phase 1 & NCT01605526 & Completed & Sarcoma \\
\hline RG7211 & Phase 1 & NCT01635296 & Completed & Myelogenous leukemia, acute \\
\hline RG7211 & Phase 1 & NCT01677780 & Completed & $\begin{array}{l}\text { Myelogenous leukemia, chronic, neoplasms, myelogenous } \\
\text { leukemia, acute }\end{array}$ \\
\hline RG7388 & Phase 1 & NCT01462175 & Completed & Neoplasms \\
\hline RG7388 & Phase 1 & NCT01773408 & Completed & Myelogenous leukemia, acute \\
\hline RG7388 & Phase 1 & NCT01901172 & Completed & Neoplasms \\
\hline RG7388 & Phase 3 & NCT02545283 & Recruiting & Leukemia, myeloid, acute \\
\hline RG7388 & Phase 1 phase 2 & NCT02633059 & Recruiting & Loss of chromosome 17p|recurrent plasma cell myeloma \\
\hline RG7388 & Phase 1 phase 2 & NCT02670044 & Recruiting & Leukemia, myeloid, acute \\
\hline RG7388 & Phase 1 phase 2 & NCT03135262 & Active, not recruiting & Follicular lymphomallymphoma, large B-cell, diffuse \\
\hline RG7388 & Phase 1 phase 2 & NCT03158389 & Recruiting & Glioblastoma, adult \\
\hline RG7388 & Phase 1 phase 2 & NCT03337698 & Recruiting & Carcinoma, non-small-cell lung \\
\hline RG7388 & Phase 1 & NCT03362723 & Completed & Solid tumors \\
\hline RG7388 & Phase 1 phase 2 & NCT03555149 & Recruiting & Colorectal cancer \\
\hline RG7388 & Phase 1 phase 2 & NCT03566485 & Active, not recruiting & $\begin{array}{l}\text { Stage III breast cancer|stage IIIA breast cancer|stage IIIB breast } \\
\text { cancer|stage IIIC breast cancer|stage IV breast cancer|estrogen } \\
\text { receptor-positive|HER2/Neu negative }\end{array}$ \\
\hline RG7388 & Phase 1 phase 2 & NCT04029688 & Recruiting & AML|ALL|neuroblastoma|solid tumors \\
\hline RG7775 & Phase 1 & NCT02098967 & Completed & Neoplasms, myelogenous leukemia, acute \\
\hline SAR405838 & Phase 1 & NCT01636479 & Completed & Neoplasm malignant \\
\hline SAR405838 & Phase 1 & NCT01985191 & Completed & Neoplasm malignant \\
\hline HDM201 & Phase 1 & NCT02143635 & Active, not recruiting & Advanced solid and hematological TP53wt tumors \\
\hline HDM201 & Phase 1 phase 2 & NCT02343172 & Active, not recruiting & Liposarcoma \\
\hline HDM201 & Phase 1 & NCT02601378 & Active, not recruiting & Uveal melanoma \\
\hline HDM201 & Phase 1 & NCT02780128 & Recruiting & Neuroblastoma|cancer \\
\hline HDM201 & Phase 1 & NCT02890069 & Recruiting & $\begin{array}{l}\text { Colorectal cancer, non-small cell lung carcinoma } \\
\text { (adenocarcinoma), triple negative breast cancer, renal cell } \\
\text { carcinoma }\end{array}$ \\
\hline HDM201 & Phase 1 & NCT03714958 & Recruiting & Colorectal cancer|advanced cancer|metastatic cancer \\
\hline HDM201 & Phase 1|phase 2 & NCT03760445 & Recruiting & Leukemia, myeloid, acute \\
\hline HDM201 & Phase 1 & NCT03940352 & Recruiting & AML|high-risk MDS \\
\hline HDM201 & Phase 2 & NCT04116541 & Not yet recruiting & Malignant solid tumor \\
\hline APG-115 & Phase 1 & NCT02935907 & Recruiting & Patients with advanced solid tumor or lymphoma \\
\hline APG-115 & Phase 1|phase 2 & NCT03611868 & Recruiting & Unresectable or metastatic melanoma or advanced solid tumors \\
\hline APG-115 & Phase 1 |phase 2 & NCT03781986 & Not yet recruiting & Malignant salivary gland cancer \\
\hline AMG-232 & Phase 1 & NCT01723020 & Completed & $\begin{array}{l}\text { Advanced malignancy|advanced solid tumors|cancer|oncology| } \\
\text { oncology patients|tumors|glioblastoma|multiple myeloma }\end{array}$ \\
\hline AMG-232 & Phase 1 & NCT02016729 & Completed & Advanced Malignancy|cancer|oncology|oncology Patients|AML \\
\hline AMG-232 & Phase 1 phase 2 & NCT02110355 & Completed & $\begin{array}{l}\text { Advanced malignancy|advanced solid tumors|cancer|oncology| } \\
\text { oncology patients|tumors|melanoma }\end{array}$ \\
\hline AMG-232 & Phase 1 & NCT03031730 & Recruiting & $\begin{array}{l}\text { Hypercalcemia|plasmacytoma|recurrent plasma cell myeloma| } \\
\text { refractory plasma cell myeloma }\end{array}$ \\
\hline AMG-232 & Phase 1 & NCT03041688 & Recruiting & AML|recurrent AML|refractory AML|secondary AML \\
\hline AMG-232 & Phase 1 & NCT03107780 & Recruiting & Glioblastoma|gliosarcoma|recurrent glioblastoma \\
\hline AMG-232 & Phase 1 & NCT03217266 & Recruiting & Soft tissue sarcoma \\
\hline AMG-232 & Phase 2 & NCT03662126 & Recruiting & PMF|Post-PV-MF|Post-ET-MF \\
\hline AMG-232 & Phase 2 & NCT03669965 & Recruiting & Polycythemia vera \\
\hline AMG-232 & Phase 2 & NCT03787602 & Recruiting & Merkel cell carcinoma \\
\hline AMG-232 & Phase 1 phase 2 & NCT04113616 & Recruiting & AML|AML, secondary to MPN \\
\hline AMG-232 & Phase 1 & NCT04190550 & Not yet recruiting & AML|AML arising from previous MDS \\
\hline MK-8242 & Phase 1 & NCT01451437 & Terminated & $\mathrm{AML}$ \\
\hline MK-8242 & Phase 1 & NCT01463696 & Terminated & Solid tumors \\
\hline
\end{tabular}

AML, acute myeloid leukemia; MDS, myelodysplastic syndrome; PMF, primary myelofibrosis; Post-PV-MF, post-polycythemia vera MF; Post-ET-MF, post-essential thrombocythemia MF; MPN, myeloproliferative neoplasms. 


\section{RG7388}

RG7388, a second-generation Nutlin, was developed to improve the potency and toxicity profile of earlier Nutlin. RG7388 induced p21 expression and effective cell cycle arrest in three cell lines MCF-7, U-2OS and SJSA-1, which proved the strong activation of p53 (Skalniak et al., 2018). RG7388 is currently undergoing several clinical examinations, including the only III clinical trial of MDM2 inhibitor (MIRROS/NCT02545283). The results of phase I clinical trial showed that RG7388 improved clinical outcomes by modulating p53 activity in AML patients with high levels of MDM2 expression (Reis et al., 2016). MIRROS is a randomized phase III clinical trial to evaluate the efficacy of RG7388 combined with cytarabine in the treatment of recurrent and refractory acute myeloid leukemia (AML). As of April 2019, the study has recruited approximately $90 \%$ of patient population and is still ongoing. If $80 \%$ of deaths are observed in p53-WT population of this study, an interim efficacy analysis can be obtained by 2020. MIRROS may obtain the first phase III clinical trial data of MDM2 inhibitors and provide a new treatment option for patients with AML (Montesinos et al., 2020).

\section{RG7775}

RG7775 is an inactive pegylated prodrug of AP (idasanutlin), which cleaves the pegylated tail of esterases in the blood. AP is a potent and selective inhibitor of p53-MDM2 interaction to activate p53 pathway and associates with cell-cycle arrest and/ or apoptosis. In a preclinical trial, intravenous (IV) RG7775 (RO6839921) showed anti-tumor effects in osteosarcoma and AML in immunocompromised mice model (Chen et al., 2019). In a phase I study (NCT02098967), RG7775 was investigated for its safety, tolerability, and pharmacokinetics in patients with advanced malignancies (Abdul et al., 2019). The result showed that RG7775 had a safety profile comparable to oral idasanutlin.

\section{SAR405838}

SAR405838 is an oral selective spirooxindole small molecule derivative antagonist of MDM2, which targets MDM2-p53 interaction (Wang et al., 2014). In the treatment of dedifferentiated liposarcoma cells, SAR405838 effectively stabilized p53, activated p53 pathway, block cell proliferation, promoted cell-cycle arrest and induced apoptosis (Bill et al., 2016). SAR405838 has been used in two clinical trials in cancer patients (NCT01636479, NCT01985191). Study of TED12318 (NCT01636479) was a phase I, open-label, dose-ranging, dose escalating, safety study administered orally in adult patients with advanced solid tumor. In this trial, 74 patients were treated with SAR405838 which showed best response in 56\% patients with a $32 \% 3$-month progression free rate. This study indicated that SAR405838 had an acceptable safety profile in patients with advanced solid tumors (de Jonge et al., 2017). Another clinical trial on SAR405838 was the study of TCD13388 (NCT01985191), which analyzed safety and efficacy of SAR405838 combined with pimasertib in cancer patients. In this study, 26 patients with locally advanced or metastatic solid tumors, who were documented to have wild-type p53 and RAS or RAF mutations, were enrolled in this study. The aim of this study was to explore maximum tolerated dose (MTD). Patient response was observed with SAR405838 at 200 or $300 \mathrm{mg}$ QD plus pimasertib $60 \mathrm{mg}$ QD or $45 \mathrm{mg}$ BID. The most frequently occurring adverse events observed were diarrhoea $(81 \%)$, blood creatine phosphokinase (77\%), nausea (62\%) and vomiting (62\%). This study indicated that the safety profile of SAR405838 combined with pimasertib was consistent with the safety profiles of both the drugs (de Weger et al., 2019).

\section{HDM201}

HDM201 is a potent and selective small molecule that inhibits the interaction between MDM2 and p53, leading to tumor regression in preclinical models with both low and high dose regimen (Seipel et al., 2018). HDM201 had a specific and effective killing effect on 553 wild-type cells with positive-ITD when used in combination with midotaline (Seipel et al., 2018). HDM201 has been used in clinal trial (NCT02143635). NCT02143635 determined and evaluated a safe and tolerated dose of HDM201 in patients with advanced tumors with wild type p53. At the time of data cut-off (April 1, 2016), 74 patients received HDM201 (Reg 1 with 38 patients and Reg 2 with 36 patients still receiving treatment). The results showed that the common grade $3 / 4$ adverse events (AEs) in both regimens (Reg 1 and Reg 2) were anemia $(8 \% ; 17 \%)$, neutropenia $(26 \% ; 14 \%)$, and thrombocytopenia $(24 \% ; 28 \%)$. Preliminary data indicated that hematological toxicity was delayed and dependent on regimen and that the Reg 1 regimen allows for higher cumulative dose (Jeay et al., 2018).

\section{APG-115}

APG-115 is a novel, orally active small-molecule MDM2 inhibitor. APG-115 restores p53 expression after binding with MDM2 and activates p53 mediated apoptosis in tumor cells with wild-type p53 (Aguilar et al., 2017). APG-115 has been used in clinical trials for treating solid tumor (NCT02935907), metastatic melanoma (NCT03611868), and salivary gland carcinoma (NCT03781986). Study NCT02935907 was a phase I study of the safety, pharmacokinetic and pharmacodynamic properties of orally administered APG-115 in patients with advanced solid tumors or lymphomas. Different dose levels (Including $10 \mathrm{mg}, 20$ $\mathrm{mg}, 50 \mathrm{mg}, 100 \mathrm{mg}, 200 \mathrm{mg}$ and $300 \mathrm{mg}$ ) were tested in this study. The result showed the optimum dose of APG-115 to be $100 \mathrm{mg}$ with no dose-limiting toxicities (Tolcher et al., 2019). In recent studies, APG-115 mediated the anti-tumor immunity of tumor microenvironment (TME). APG-115 activated p53 and p21 on bone marrow-derived macrophages in vitro, and reduced the number of immunosuppressive M2 macrophages by downregulating c-Myc and c-Maf. In addition, APG-115 showed costimulatory activity in $\mathrm{T}$ cells and increased the expression of PD-L1 in tumor cells. This evidence suggests the combination of APG and immunotherapy may be a new anti-tumor regimen (Fang et al., 2019).

\section{AMG 232}

AMG 232 is an investigational oral, selective MDM2 inhibitor that restores p53 tumor suppression by blocking MDM2-p53 interaction (Sun et al., 2014). The activity of AMG 232 and its 
effect on p53 signal were characterized in several preclinical tumor models. AMG 232 bind MDM2, strongly induced p53 activity, lead to cell cycle arrest and inhibit tumor cell proliferation (Canon et al., 2015). Several clinical trials of the AMG 232 such as NCT01723020, NCT02016729, NCT02110355, NCT03031730, NCT03041688, NCT03107780, and NCT03217266 have been ongoing to treat human cancers. NCT02016729 was an open-label phase I study that evaluated the safety, pharmacokinetics, and MTD of AMG 232. In this study, AMG 232 was administered in two regimens (arm 1 and arm 2). Patients were treated with AMG 232 at 60, 120, 240, 360, 480, or $960 \mathrm{mg}$ as monotherapy once daily for $7 \mathrm{~d}$ every 2 weeks in arm 1 or at $60 \mathrm{mg}$ combined with trametinib at $2 \mathrm{mg}$ in arm 2. The results exhibited common treatment-related AEs included nausea (58\%), diarrhea (56\%), vomiting (33\%), and decreased appetite (25\%). However, the MTD of AMG 232 was not reached. Dose escalation was discontinued because of its unacceptable gastrointestinal AEs at higher doses (Erba et al., 2019).

\section{MK-8242}

MK-8242 is a potent, small-molecule inhibitor which targets MDM2-p53 interaction (Kang et al., 2016). MK-8242 induced tumor regression of various solid tumor types and complete or partial response in most acute lymphoblastic leukemia xenografts (Kang et al., 2016). MK-8242 has been used in two Phase I clinical trials (NCT01451437 and NCT01463696). Study of NCT01451437 was a study of MK-8242 alone and in combination with cytarabine in adult participants with refractory or recurrent AML. In this study MK-8242 was administered at 30-250 mg (p.o;QD) or 120-250 mg (p.o;BID) for $7 \mathrm{~d}$ on/7 $\mathrm{d}$ off in a 28 -d cycle and optimized regimen was administered at 210 or $300 \mathrm{mg}$ (p.o;BID) for $7 \mathrm{on} / 14$ off in $21-\mathrm{d}$ cycle. Twenty-six patients were enrolled in this study, out of which 5 discontinued because of AEs and 7 patients died. This study showed the $7 \mathrm{on} / 14$ off regimen had a more favorable safety profile than the 7 on/7 off regimen (Ravandi et al., 2016). NCT01463696 was aimed at evaluating the safety and pharmacokinetic profile of MK-8242 in patients with advanced solid tumors. In this study, drug dose was escalated to determine the MTD in part 1 and the MTD was confirmed and the recommended Phase 2 dose (RPTD) was established in part 2. Finally, 47 patients were enrolled in this study and treated with MK-8242 at eight level doses that ranged from 60 to $500 \mathrm{mg}$. The result showed that MK-8242 activated p53 pathway with an acceptable tolerability profile at $400 \mathrm{mg}$ (BID) (Wagner et al., 2017).

\section{MDM2-Based Multi-Target Inhibitors}

Along with the development of MDM2 inhibitors, searching for multi-target inhibitors may be a new research direction. MDM2based multi-target inhibitors could improve the efficacy and reduce the side effects (de Lera and Ganesan, 2016). Dual inhibitors that have been reported to be co-inhibit with MDM2 include MDM4, NF- $\kappa \mathrm{B}$, histone deacetylases (HDAC), translocator protein (TSPO), XIAP, and integrins (McCormack et al., 2012; Daniele et al., 2016; Gu et al., 2016; Shirai et al., 2016; Giustiniano et al., 2017; Merlino et al., 2018), which achieved excellent in vitro and in vivo antitumor potency. Considering MDM2 and MDM4 dual inhibitors had been well reviewed in the recent literature (Teveroni et al., 2016; Espadinha et al., 2018), we summarize other dual inhibitors.

\section{Dual Inhibitors of MDM2 and NF- $\mathrm{KB}$}

Nuclear transcription factor $(\mathrm{NF}-\kappa \mathrm{B})$ is a class of key nuclear transcription factors exist in the cytoplasm of almost all types cells in the form of homologous or heterodime. NF- $\kappa \mathrm{B}$ family includes five DNA-binding proteins that are usually overexpressed in mammalian cancer cell (Pahl, 1999). Previous studies found that NF- $\kappa \mathrm{B}$ inhibit p53 stability by directly upregulating MDM2 (Dey et al., 2008). The cross-talk between p53 and NF- $\kappa B$ showed that simultaneous activation of p53 and inhibition of NF- $\kappa B$ would provide a synergistic effect on antitumor activity. Zhang et al. designed a series of pyrrolo[3,4-c] pyrazole derivatives and synthesized as the first-in-class inhibitors for both p53-MDM2 interaction and NF- $\kappa B$. These compounds effective targeted p53-MDM2 interaction and inhibit cell growth in A549 xenograft model (Zhuang et al., 2014). In addition, dual-target inhibitors enhanced the anti-tumor effect of radiotherapy in pancreatic cancer (Shirai et al., 2016).

\section{Dual Inhibitors of MDM2 and HDAC}

Histone deacetylase (HDAC) is a kind of epigenetic enzyme plays an important role in the regulation of tumor suppressor genes (Kouzarides, 2007). In recent years, more HDAC inhibitors have been approved by FDA such as romidepsin and vorinostat (Mann et al., 2007). Most of the inhibitors used in clinic are not effective in the treatment of solid tumors, and they are also limited in the treatment of hematological malignant tumors (Tan et al., 2010). Recent studies showed that HDAC inhibitors cooperated with MDM2 inhibitors to suppress the proliferation of tumor cells (McCormack et al., 2012). Inhibition of HDAC not only lead to the accumulation of activated p53, but also modified the hyperacetylation of p53 to enhance the antitumor activity of MDM2 inhibitors (Xu et al., 2007; McCormack et al., 2012). He et al. designed and synthesized the first MDM2/ HDAC dual inhibitor according to the known binding model of MDM2 and HDAC inhibitors. These synthetic compounds showed excellent targeted inhibitory effects on HDAC and MDM2 in analysis of biochemical evaluation and structureactivity relationship as well as good anti-tumor activity in the xenograft model of A549 in vivo (He et al., 2018). These studies suggest that inhibitors targeting both HDAC and MDM2 may be a new way to treat cancer.

\section{Dual Inhibitors of MDM2 and TSPO}

The translocation protein (TSPO) is an $18 \mathrm{kDa}$ transmembrane protein, which mainly exists in the outer membrane of mitochondria and constitutes a key part of the mitochondrial permeability transition pore (MPTP) (Austin et al., 2013). MPTP 
could affect apoptosis by regulating mitochondrial outer membrane permeabilization (MOMP) (Tait and Green, 2010), suggesting TSPO as a useful target to trigger cellular apoptosis (Chelli et al., 2005). Welsch.et al confirmed that multi-target single molecules of TSPO and MDM2 would enhance the antitumor efficacy (Welsch et al., 2010). A 2-phenylindolylglyoxylyl dipeptide was designed to bind TSPO, leading to the disruption of MDM2-p53 interaction, cell-cycle arrest, and apoptosis in human GBM cells (Daniele et al., 2016).

\section{Dual Inhibitors of MDM2 and XIAP}

XIAP belongs to IAP family, which can down-regulate the mitochondrial apoptosis by inhibiting caspase 3,7 , and 9. XIAP is highly expressed in various types of cancer and is related to poor outcome (Tamm et al., 2004; Berezovskaya et al., 2005; Mizutani et al., 2007). The binding between IRES region of XIAP and MDM2 induced translation enhancement of XIAP and stability of MDM2 (Candeias et al., 2008; Liu et al., 2015). Zhou et al. developed a protein-RNA fluorescence polarization (FP) assay for high-throughput screening (HTS) of chemical libraries and identified eight inhibitors blocking the MDM2 protein-XIAP RNA interaction. The compound-induced MDM2 downregulation resulted in inhibition of XIAP expression and in activation of p53, which contributed to cell apoptosis and proliferation inhibition (Gu et al., 2016).

\section{Dual Inhibitors of MDM2 and Integrins}

Fibronectin is a gene cluster related to highly malignant glioblastoma and includes main receptors $\alpha 5 \beta 1, \alpha v \beta 6, \alpha v \beta 8$, and $\alpha v \beta 3$ integrins (Dechantsreiter et al., 1999; Mas-Moruno et al., 2010). A selective antagonist of integrin receptors perturbed $\alpha 5 \beta 1$ function, provoked cell cycle arrest and decreased cell aggressiveness (Maglott et al., 2006). An effective $\alpha 5 \beta 1 / \alpha v \beta 3$ integrin binding agent was identified to inhibit MDM2/4 activity and reactivated p53 pathway. In addition, this compound can induce cell cycle arrest, reduce the invasiveness of GBM cells and block the proliferation of p53 wild-type GBM cells (Merlino et al., 2018). The novel class of integrin/MDM2 inhibitors is useful in the subpopulation of patients with glioblastoma expressing functional p53 concomitantly with a high level of $\alpha 5 \beta 1$ integrin (Merlino et al., 2018).

\section{REFERENCES}

Abdul, R. A., Miller, W. J., Uy, G. L., Blotner, S., Young, A. M., Higgins, B., et al. (2019). A phase 1 study of the MDM2 antagonist RO6839921, a pegylated prodrug of idasanutlin, in patients with advanced solid tumors. Invest. New Drugs. doi: 10.1007/s10637-019-00869-2

Aguilar, A., Lu, J., Liu, L., Du, D., Bernard, D., McEachern, D., et al. (2017).

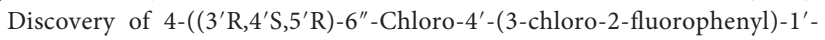
ethyl-2" -oxodispiro[ cyclohexane-1, $2^{\prime}$-pyrrolidine- $3^{\prime}, 3^{\prime \prime}$-indoline]-5'carboxamido)bicyclo[2.2.2] octane-1-carboxylic Acid (AA-115/APG-115): A Potent and Orally Active Murine Double Minute 2 (MDM2) Inhibitor in Clinical Development. J. Med. Chem. 60 (7), 2819-2839. doi: 10.1021/ acs.jmedchem.6b01665

\section{CONCLUSION}

Genotoxic attacks are a huge threat to genomic stability. With the major role of $\mathrm{p} 53$ in maintaining genome integrity, it is a big challenge to dissect out diverse regulatory roles of $\mathrm{p} 53$. Since the first identification of MDM2 cDNA repeats in transformed mouse 3T3 cells, evidence has increasing supported the functions of MDM2 in regulating cell proliferation, senescence, DNA repair, and apoptosis through p53dependent and p53-independent pathways. MDM2 forms a large protein interactome to participate in different signal pathways, with the consideration of its changed protein conformations, modulated protein isoforms, tightly regulated post-translational modifications and subcellular localization. MDM2 keeps p53 content to a basal level in normal conditions. In response to stress signals like DNA damage, both MDM2 and p53 undergo diverse post-translational modifications, resulting in p53 stability and activation to regulate target genes transcription. One of the strategies for drug discovery is to improve p53 activity by inhibiting MDM2p53 interaction. Further studies are needed to clarify the cell fate determination by MDM2-p53 axis after DNA damage and other regulatory pathways of MDM2 protein, especially the diverse isoforms of MDM2 in DNA repair process.

\section{AUTHOR CONTRIBUTIONS}

All authors substantially contributed to this work. WL and XP designed and performed original draft. WL and XP contributed to figure and table preparation. WL, JL, and CX reviewed and edited the manuscript. All authors have read and agreed to the published version of the manuscript.

\section{FUNDING}

This study was supported by the National Natural Science Foundation of China (No.81572892, No. 81873048).
Aguilera, A., and Garcia-Muse, T. (2013). Causes of genome instability. Annu. Rev. Genet. 47, 1-32. doi: 10.1146/annurev-genet-111212-133232

Alt, J. R., Bouska, A., Fernandez, M. R., Cerny, R. L., Xiao, H., and Eischen, C. M. (2005). Mdm2 binds to Nbs1 at sites of DNA damage and regulates double strand break repair. J. Biol. Chem. 280 (19), 18771-18781. doi: 10.1074/ jbc.M413387200

Appella, E., and Anderson, C. W. (2001). Post-translational modifications and activation of p53 by genotoxic stresses. Eur. J. Biochem. 268 (10), 2764-2772. doi: 10.1046/j.1432-1327.2001.02225.x

Arva, N. C., Gopen, T. R., Talbott, K. E., Campbell, L. E., Chicas, A., White, D. E., et al. (2005). A chromatin-associated and transcriptionally inactive p53-Mdm2 complex occurs in mdm2 SNP309 homozygous cells. J. Biol. Chem. 280 (29), 26776-26787. doi: 10.1074/jbc.M505203200 
Asahara, H., Li, Y., Fuss, J., Haines, D. S., Vlatkovic, N., Boyd, M. T., et al. (2003). Stimulation of human DNA polymerase epsilon by MDM2. Nucleic Acids Res. 31 (9), 2451-2459. doi: 10.1093/nar/gkg342

Austin, C. J., Kahlert, J., Kassiou, M., and Rendina, L. M. (2013). The translocator protein (TSPO): a novel target for cancer chemotherapy. Int. J. Biochem. Cell Biol. 45 (7), 1212-1216. doi: 10.1016/j.biocel.2013.03.004

Barak, Y., Gottlieb, E., Juven-Gershon, T., and Oren, M. (1994). Regulation of mdm2 expression by p53: alternative promoters produce transcripts with nonidentical translation potential. Genes Dev. 8 (15), 1739-1749. doi: $10.1101 /$ gad.8.15.1739

Baskaran, R., Wood, L. D., Whitaker, L. L., Canman, C. E., Morgan, S. E., Xu, Y., et al. (1997). Ataxia telangiectasia mutant protein activates c-Abl tyrosine kinase in response to ionizing radiation. Nature 387 (6632), 516-519. doi: $10.1038 / 387516 \mathrm{a} 0$

Berezovskaya, O., Schimmer, A. D., Glinskii, A. B., Pinilla, C., Hoffman, R. M., Reed, J. C., et al. (2005). Increased expression of apoptosis inhibitor protein XIAP contributes to anoikis resistance of circulating human prostate cancer metastasis precursor cells. Cancer Res. 65 (6), 2378-2386. doi: 10.1158/00085472.CAN-04-2649

Bernardi, R., Scaglioni, P. P., Bergmann, S., Horn, H. F., Vousden, K. H., and Pandolfi, P. P. (2004). PML regulates p53 stability by sequestering Mdm2 to the nucleolus. Nat. Cell Biol. 6 (7), 665-672. doi: 10.1038/ncb1147

Bill, K. L., Garnett, J., Meaux, I., Ma, X., Creighton, C. J., Bolshakov, S., et al. (2016). SAR405838: A Novel and Potent Inhibitor of the MDM2:p53 Axis for the Treatment of Dedifferentiated Liposarcoma. Clin. Cancer Res. 22 (5), 11501160. doi: 10.1158/1078-0432.CCR-15-1522

Blattner, C., Hay, T., Meek, D. W., and Lane, D. P. (2002). Hypophosphorylation of Mdm2 augments p53 stability. Mol. Cell Biol. 22 (17), 6170-6182. doi: $10.1128 / \mathrm{mcb} .22 .17 .6170-6182.2002$

Bond, G. L., and Levine, A. J. (2007). A single nucleotide polymorphism in the p53 pathway interacts with gender, environmental stresses and tumor genetics to influence cancer in humans. Oncogene 26 (9), 1317-1323. doi: 10.1038/ sj.onc. 1210199

Bond, G. L., Hu, W., Bond, E. E., Robins, H., Lutzker, S. G., Arva, N. C., et al. (2004). A single nucleotide polymorphism in the MDM2 promoter attenuates the p53 tumor suppressor pathway and accelerates tumor formation in humans. Cell 119 (5), 591-602. doi: 10.1016/j.cell.2004.11.022

Bosch-Presegue, L., Raurell-Vila, H., Marazuela-Duque, A., Kane-Goldsmith, N., Valle, A., Oliver, J., et al. (2011). Stabilization of Suv39H1 by SirT1 is part of oxidative stress response and ensures genome protection. Mol. Cell 42 (2), 210223. doi: 10.1016/j.molcel.2011.02.034

Bottger, A., Bottger, V., Sparks, A., Liu, W. L., Howard, S. F., and Lane, D. P. (1997). Design of a synthetic Mdm2-binding mini protein that activates the p53 response in vivo. Curr. Biol. 7 (11), 860-869. doi: 10.1016/s0960-9822(06) 00374-5

Bouska, A., and Eischen, C. M. (2009). Mdm2 affects genome stability independent of p53. Cancer Res. 69 (5), 1697-1701. doi: 10.1158/0008-5472.CAN-08-3732

Bouska, A., Lushnikova, T., Plaza, S., and Eischen, C. M. (2008). Mdm2 promotes genetic instability and transformation independent of p53. Mol. Cell Biol. 28 (15), 4862-4874. doi: 10.1128/MCB.01584-07

Boyd, S. D., Tsai, K. Y., and Jacks, T. (2000). An intact HDM2 RING-finger domain is required for nuclear exclusion of p53. Nat. Cell Biol. 2 (9), 563-568. doi: $10.1038 / 35023500$

Brown, L., and McCarthy, N. (1997). DNA repair. A sense-abl response? Nature 387 (6632), 450-451. doi: 10.1038/387450a0

Bunting, S. F., and Nussenzweig, A. (2013). End-joining, translocations and cancer. Nat. Rev. Cancer 13 (7), 443-454. doi: 10.1038/nrc3537

Buschmann, T., Fuchs, S. Y., Lee, C. G., Pan, Z. Q., and Ronai, Z. (2000). SUMO-1 modification of $\mathrm{Mdm} 2$ prevents its self-ubiquitination and increases $\mathrm{Mdm} 2$ ability to ubiquitinate p53. Cell 101 (7), 753-762. doi: 10.1016/s0092-8674(00) 80887-9

Buschmann, T., Lerner, D., Lee, C. G., and Ronai, Z. (2001). The Mdm-2 amino terminus is required for Mdm2 binding and SUMO-1 conjugation by the E2 SUMO-1 conjugating enzyme Ubc9. J. Biol. Chem. 276 (44), 40389-40395. doi: 10.1074/jbc.M103786200

Candeias, M. M., Malbert-Colas, L., Powell, D. J., Daskalogianni, C., Maslon, M. M., Naski, N., et al. (2008). P53 mRNA controls p53 activity by managing Mdm2 functions. Nat. Cell Biol. 10 (9), 1098-1105. doi: 10.1038/ncb1770
Canon, J., Osgood, T., Olson, S. H., Saiki, A. Y., Robertson, R., Yu, D., et al. (2015). The MDM2 Inhibitor AMG 232 Demonstrates Robust Antitumor Efficacy and Potentiates the Activity of p53-Inducing Cytotoxic Agents. Mol. Cancer Ther. 14 (3), 649-658. doi: 10.1158/1535-7163.MCT-14-0710

Cao, Z., Xue, J., Cheng, Y., Wang, J., Liu, Y., Li, H., et al. (2019). MDM2 promotes genome instability by ubiquitinating the transcription factor HBP1. Oncogene 38 (24), 4835-4855. doi: 10.1038/s41388-019-0761-2

Carroll, P. E., Okuda, M., Horn, H. F., Biddinger, P., Stambrook, P. J., Gleich, L. L., et al. (1999). Centrosome hyperamplification in human cancer: chromosome instability induced by 553 mutation and/or Mdm2 overexpression. Oncogene 18 (11), 1935-1944. doi: 10.1038/sj.onc.1202515

Chang, Y. C., Lee, Y. S., Tejima, T., Tanaka, K., Omura, S., Heintz, N. H., et al. (1998). mdm 2 and bax, downstream mediators of the p53 response, are degraded by the ubiquitin-proteasome pathway. Cell Growth Differ. 9 (1), 79-84.

Chelli, B., Rossi, L., Da, P. E., Costa, B., Spinetti, F., Rechichi, M., et al. (2005). PIGA (N,N-Di-n-butyl-5-chloro-2-(4-chlorophenyl)indol-3-ylglyoxylamide), a new mitochondrial benzodiazepine-receptor ligand, induces apoptosis in C6 glioma cells. Chembiochem 6 (6), 1082-1088. doi: 10.1002/cbic.200400350

Chen, L., Pastorino, F., Berry, P., Bonner, J., Kirk, C., Wood, K. M., et al. (2019). Preclinical evaluation of the first intravenous small molecule MDM2 antagonist alone and in combination with temozolomide in neuroblastoma. Int. J. Cancer 144 (12), 3146-3159. doi: 10.1002/ijc.32058

Cheng, Q., Chen, L., Li, Z., Lane, W. S., and Chen, J. (2009). ATM activates p53 by regulating MDM2 oligomerization and E3 processivity. EMBO J. 28 (24), 3857-3867. doi: 10.1038/emboj.2009.294

Cheng, Q., Cross, B., Li, B., Chen, L., Li, Z., and Chen, J. (2011). Regulation of MDM2 E3 ligase activity by phosphorylation after DNA damage. Mol. Cell Biol. 31 (24), 4951-4963. doi: 10.1128/MCB.05553-11

Chiu, S. Y., Asai, N., Costantini, F., and Hsu, W. (2008). SUMO-specific protease 2 is essential for modulating p53-Mdm2 in development of trophoblast stem cell niches and lineages. PloS Biol. 6 (12), e310. doi: 10.1371/journal.pbio.0060310

Ciccia, A., and Elledge, S. J. (2010). The DNA damage response: making it safe to play with knives. Mol. Cell 40 (2), 179-204. doi: 10.1016/j.molcel.2010.09.019

Cross, B., Chen, L., Cheng, Q., Li, B., Yuan, Z. M., and Chen, J. (2011). Inhibition of p53 DNA binding function by the MDM2 protein acidic domain. J. Biol. Chem. 286 (18), 16018-16029. doi: 10.1074/jbc.M111.228981

D'Amours, D., and Jackson, S. P. (2002). The Mre11 complex: at the crossroads of dna repair and checkpoint signalling. Nat. Rev. Mol. Cell Biol. 3 (5), 317-327. doi: 10.1038/nrm805

Daniele, S., La Pietra, V., Barresi, E., Di Maro, S., Da, P. E., Robello, M., et al. (2016). Lead Optimization of 2-Phenylindolylglyoxylyldipeptide Murine Double Minute (MDM)2/Translocator Protein (TSPO) Dual Inhibitors for the Treatment of Gliomas. J. Med. Chem. 59 (10), 4526-4538. doi: 10.1021/ acs.jmedchem.5b01767

Davies, H., Bignell, G. R., Cox, C., Stephens, P., Edkins, S., Clegg, S., et al. (2002). Mutations of the BRAF gene in human cancer. Nature 417 (6892), 949-954. doi: $10.1038 /$ nature 00766

de Jonge, M., de Weger, V. A., Dickson, M. A., Langenberg, M., Le Cesne, A., Wagner, A. J., et al. (2017). A phase I study of SAR405838, a novel human double minute 2 (HDM2) antagonist, in patients with solid tumours. Eur. J. Cancer 76, 144-151. doi: 10.1016/j.ejca.2017.02.005

de Lera, A. R., and Ganesan, A. (2016). Epigenetic polypharmacology: from combination therapy to multitargeted drugs. Clin. Epigenet. 8, 105. doi: 10.1186/s13148-016-0271-9

de Toledo, S. M., Azzam, E. I., Dahlberg, W. K., Gooding, T. B., and Little, J. B. (2000). ATM complexes with HDM2 and promotes its rapid phosphorylation in a p53-independent manner in normal and tumor human cells exposed to ionizing radiation. Oncogene 19 (54), 6185-6193. doi: 10.1038/sj.onc.1204020

de Weger, V. A., de Jonge, M., Langenberg, M., Schellens, J., Lolkema, M., Varga, A., et al. (2019). A phase I study of the HDM2 antagonist SAR405838 combined with the MEK inhibitor pimasertib in patients with advanced solid tumours. Br. J. Cancer 120 (3), 286-293. doi: 10.1038/s41416-0180355-8

Dechantsreiter, M. A., Planker, E., Matha, B., Lohof, E., Holzemann, G., Jonczyk, A., et al. (1999). N-Methylated cyclic RGD peptides as highly active and selective alpha(V)beta(3) integrin antagonists. J. Med. Chem. 42 (16), 30333040. doi: $10.1021 / j m 970832 \mathrm{~g}$ 
Dey, A., Tergaonkar, V., and Lane, D. P. (2008). Double-edged swords as cancer therapeutics: simultaneously targeting $\mathrm{p} 53$ and NF-kappaB pathways. Nat. Rev. Drug Discovery 7 (12), 1031-1040. doi: 10.1038/nrd2759

Dias, S. S., Milne, D. M., and Meek, D. W. (2006). c-Abl phosphorylates Hdm2 at tyrosine 276 in response to DNA damage and regulates interaction with ARF. Oncogene 25 (50), 6666-6671. doi: 10.1038/sj.onc.1209671

Donehower, L. A., Harvey, M., Slagle, B. L., McArthur, M. J., Montgomery, C. J., Butel, J. S., et al. (1992). Mice deficient for p53 are developmentally normal but susceptible to spontaneous tumours. Nature 356 (6366), 215-221. doi: 10.1038/ $356215 \mathrm{a} 0$

Eischen, C. M., and Lozano, G. (2014). The Mdm network and its regulation of p53 activities: a rheostat of cancer risk. Hum. Mutat. 35 (6), 728-737. doi: 10.1002/humu.22524

Eischen, C. M., Weber, J. D., Roussel, M. F., Sherr, C. J., and Cleveland, J. L. (1999). Disruption of the ARF-Mdm2-p53 tumor suppressor pathway in Myc-induced lymphomagenesis. Genes Dev. 13 (20), 2658-2669. doi: 10.1101/gad.13.20.2658

Eischen, C. M. (2017). Role of Mdm2 and Mdmx in DNA repair. J. Mol. Cell Biol. 9 (1), 69-73. doi: 10.1093/jmcb/mjw052

Erba, H. P., Becker, P. S., Shami, P. J., Grunwald, M. R., Flesher, D. L., Zhu, M., et al. (2019). Phase $1 \mathrm{~b}$ study of the MDM2 inhibitor AMG 232 with or without trametinib in relapsed/refractory acute myeloid leukemia. Blood Adv. 3 (13), 1939-1949. doi: 10.1182/bloodadvances.2019030916

Espadinha, M., Barcherini, V., Lopes, E. A., and Santos, M. (2018). An Update on MDMX and Dual MDM2/X Inhibitors. Curr. Top. Med. Chem. 18 (8), 647660. doi: 10.2174/1568026618666180604080119

Evans, S. C., Viswanathan, M., Grier, J. D., Narayana, M., El-Naggar, A. K., and Lozano, G. (2001). An alternatively spliced HDM2 product increases p53 activity by inhibiting HDM2. Oncogene 20 (30), 4041-4049. doi: 10.1038/ sj.onc. 1204533

Evdokiou, A., Atkins, G. J., Bouralexis, S., Hay, S., Raggatt, L. J., Cowled, P. A., et al. (2001). Expression of alternatively-spliced MDM2 transcripts in giant cell tumours of bone. Int. J. Oncol. 19 (3), 625-632. doi: 10.3892/ijo.19.3.625

Fahraeus, R., and Olivares-Illana, V. (2014). MDM2's social network. Oncogene 33 (35), 4365-4376. doi: 10.1038/onc.2013.410

Fang, S., Jensen, J. P., Ludwig, R. L., Vousden, K. H., and Weissman, A. M. (2000). $\mathrm{Mdm} 2$ is a RING finger-dependent ubiquitin protein ligase for itself and p53. J. Biol. Chem. 275 (12), 8945-8951. doi: 10.1074/jbc.275.12.8945

Fang, D. D., Tang, Q., Kong, Y., Wang, Q., Gu, J., Fang, X., et al. (2019). MDM2 inhibitor APG-115 synergizes with PD-1 blockade through enhancing antitumor immunity in the tumor microenvironment. J. Immunother. Cancer 7 (1), 327. doi: 10.1186/s40425-019-0750-6

Freedman, D. A., Wu, L., and Levine, A. J. (1999). Functions of the MDM2 oncoprotein. Cell Mol. Life Sci. 55 (1), 96-107. doi: 10.1007/s000180050273

Frum, R. A., Singh, S., Vaughan, C., Mukhopadhyay, N. D., Grossman, S. R., Windle, B., et al. (2014). The human oncoprotein MDM2 induces replication stress eliciting early intra-S-phase checkpoint response and inhibition of DNA replication origin firing. Nucleic Acids Res. 42 (2), 926-940. doi: 10.1093/nar/gkt944

Ganem, N. J., Storchova, Z., and Pellman, D. (2007). Tetraploidy, aneuploidy and cancer. Curr. Opin. Genet. Dev. 17 (2), 157-162. doi: 10.1016/j.gde.2007.02.011

Geyer, R. K., Yu, Z. K., and Maki, C. G. (2000). The MDM2 RING-finger domain is required to promote p53 nuclear export. Nat. Cell Biol. 2 (9), 569-573. doi: $10.1038 / 35023507$

Gill, G. (2003). Post-translational modification by the small ubiquitin-related modifier SUMO has big effects on transcription factor activity. Curr. Opin. Genet. Dev. 13 (2), 108-113. doi: 10.1016/s0959-437x(03)00021-2

Giustiniano, M., Daniele, S., Pelliccia, S., La Pietra, V., Pietrobono, D., Brancaccio, D., et al. (2017). Computer-Aided Identification and Lead Optimization of Dual Murine Double Minute 2 and 4 Binders: Structure-Activity Relationship Studies and Pharmacological Activity. J. Med. Chem. 60 (19), 8115-8130. doi: 10.1021/acs.jmedchem.7b00912

Goldberg, Z., Vogt, S. R., Berger, M., Zwang, Y., Perets, R., Van Etten, R. A., et al. (2002). Tyrosine phosphorylation of $\mathrm{Mdm} 2$ by c-Abl: implications for p53 regulation. EMBO J. 21 (14), 3715-3727. doi: 10.1093/emboj/cdf384

Gotz, C., Kartarius, S., Scholtes, P., Nastainczyk, W., and Montenarh, M. (1999). Identification of a CK2 phosphorylation site in mdm2. Eur. J. Biochem. 266 (2), 493-501. doi: 10.1046/j.1432-1327.1999.00882.x

Gryshchenko, I., Hofbauer, S., Stoecher, M., Daniel, P. T., Steurer, M., Gaiger, A., et al. (2008). MDM2 SNP309 is associated with poor outcome in B-cell chronic lymphocytic leukemia. J. Clin. Oncol. 26 (14), 2252-2257. doi: 10.1200/ JCO.2007.11.5212

Gu, L., Zhang, H., Liu, T., Zhou, S., Du, Y., Xiong, J., et al. (2016). Discovery of Dual Inhibitors of MDM2 and XIAP for Cancer Treatment. Cancer Cell 30 (4), 623-636. doi: 10.1016/j.ccell.2016.08.015

Harper, J. W., and Elledge, S. J. (2007). The DNA damage response: Ten years after. Mol. Cell 28 (5), 739-745. doi: 10.1016/j.molcel.2007.11.015

Haupt, Y., Maya, R., Kazaz, A., and Oren, M. (1997). Mdm2 promotes the rapid degradation of p53. Nature 387 (6630), 296-299. doi: 10.1038/387296a0

He, S., Dong, G., Wu, S., Fang, K., Miao, Z., Wang, W., et al. (2018). Small Molecules Simultaneously Inhibiting p53-Murine Double Minute 2 (MDM2) Interaction and Histone Deacetylases (HDACs): Discovery of Novel Multitargeting Antitumor Agents. J. Med. Chem. 61 (16), 7245-7260. doi: 10.1021/acs.jmedchem.8b00664

Hirata, H., Hinoda, Y., Kikuno, N., Kawamoto, K., Suehiro, Y., Tanaka, Y., et al. (2007). MDM2 SNP309 polymorphism as risk factor for susceptibility and poor prognosis in renal cell carcinoma. Clin. Cancer Res. 13 (14), 4123-4129. doi: 10.1158/1078-0432.CCR-07-0609

Hjerrild, M., Milne, D., Dumaz, N., Hay, T., Issinger, O. G., and Meek, D. (2001). Phosphorylation of murine double minute clone 2 (MDM2) protein at serine267 by protein kinase CK2 in vitro and in cultured cells. Biochem. J. 355 (Pt 2), 347-356. doi: 10.1042/0264-6021:3550347

Hoeijmakers, J. H. (2009). DNA damage, aging, and cancer. N Engl. J. Med. 361 (15), 1475-1485. doi: 10.1056/NEJMra0804615

Honda, R., and Yasuda, H. (2000). Activity of MDM2, a ubiquitin ligase, toward p53 or itself is dependent on the RING finger domain of the ligase. Oncogene 19 (11), 1473-1476. doi: 10.1038/sj.onc.1203464

Hong, Y., Miao, X., Zhang, X., Ding, F., Luo, A., Guo, Y., et al. (2005). The role of P53 and MDM2 polymorphisms in the risk of esophageal squamous cell carcinoma. Cancer Res. 65 (20), 9582-9587. doi: 10.1158/0008-5472.CAN-05-1460

Huun, J., Gansmo, L. B., Mannsaker, B., Iversen, G. T., Ovrebo, J. I., Lonning, P. E., et al. (2017). Impact of the MDM2 splice-variants MDM2-A, MDM2-B and MDM2-C on cytotoxic stress response in breast cancer cells. BMC Cell Biol. 18 (1), 17. doi: 10.1186/s12860-017-0134-Z

Itahana, K., Mao, H., Jin, A., Itahana, Y., Clegg, H. V., Lindstrom, M. S., et al. (2007). Targeted inactivation of Mdm2 RING finger E3 ubiquitin ligase activity in the mouse reveals mechanistic insights into p53 regulation. Cancer Cell 12 (4), 355-366. doi: 10.1016/j.ccr.2007.09.007

Jacks, T., Remington, L., Williams, B. O., Schmitt, E. M., Halachmi, S., Bronson, R. T., et al. (1994). Tumor spectrum analysis in p53-mutant mice. Curr. Biol. 4 (1), 1-7. doi: 10.1016/s0960-9822(00)00002-6

Jackson, S. P., and Bartek, J. (2009). The DNA-damage response in human biology and disease. Nature 461 (7267), 1071-1078. doi: 10.1038/nature08467

Jasin, M. (2000). Chromosome breaks and genomic instability. Cancer Invest. 18 (1), 78-86. doi: 10.3109/07357900009023065

Jeay, S., Ferretti, S., Holzer, P., Fuchs, J., Chapeau, E. A., Wartmann, M., et al. (2018). Dose and Schedule Determine Distinct Molecular Mechanisms Underlying the Efficacy of the p53-MDM2 Inhibitor HDM201. Cancer Res. 78 (21), 6257-6267. doi: 10.1158/0008-5472.CAN-18-0338

Jeyaraj, S., O'Brien, D. M., and Chandler, D. S. (2009). MDM2 and MDM4 splicing: an integral part of the cancer spliceome. Front. Biosci. (Landmark Ed) 14, 2647-2656. doi: $10.2741 / 3402$

Jones, S. N., Roe, A. E., Donehower, L. A., and Bradley, A. (1995). Rescue of embryonic lethality in Mdm2-deficient mice by absence of p53. Nature 378 (6553), 206-208. doi: 10.1038/378206a0

Jones, S. N., Hancock, A. R., Vogel, H., Donehower, L. A., and Bradley, A. (1998). Overexpression of $\mathrm{Mdm} 2$ in mice reveals a p53-independent role for $\mathrm{Mdm} 2$ in tumorigenesis. Proc. Natl. Acad. Sci. U. S. A 95 (26), 15608-15612. doi: $10.1073 /$ pnas.95.26.15608

Kang, M. H., Reynolds, C. P., Kolb, E. A., Gorlick, R., Carol, H., Lock, R., et al. (2016). Initial Testing (Stage 1) of MK-8242-A Novel MDM2 Inhibitor-by the Pediatric Preclinical Testing Program. Pediatr. Blood Cancer 63 (10), 17441752. doi: $10.1002 / p b c .26064$

Kimura, S. H., and Nojima, H. (2002). Cyclin G1 associates with MDM2 and regulates accumulation and degradation of p53 protein. Genes Cells 7 (8), 869880. doi: 10.1046/j.1365-2443.2002.00564.x

Kouzarides, T. (2007). Chromatin modifications and their function. Cell 128 (4), 693-705. doi: 10.1016/j.cell.2007.02.005 
Kruse, J. P., and Gu, W. (2009). Modes of p53 regulation. Cell 137 (4), 609-622. doi: 10.1016/j.cell.2009.04.050

Kubbutat, M. H., Jones, S. N., and Vousden, K. H. (1997). Regulation of p53 stability by Mdm2. Nature 387 (6630), 299-303. doi: 10.1038/387299a0

Ladanyi, M., Cha, C., Lewis, R., Jhanwar, S. C., Huvos, A. G., and Healey, J. H. (1993). MDM2 gene amplification in metastatic osteosarcoma. Cancer Res. 53 (1), 16-18.

Lai, Z., Ferry, K. V., Diamond, M. A., Wee, K. E., Kim, Y. B., Ma, J., et al. (2001). Human $\mathrm{mdm} 2$ mediates multiple mono-ubiquitination of $\mathrm{p} 53$ by a mechanism requiring enzyme isomerization. J. Biol. Chem. 276 (33), 31357-31367. doi: $10.1074 /$ jbc.M011517200

Lawlor, M. A., and Alessi, D. R. (2001). PKB/Akt: a key mediator of cell proliferation, survival and insulin responses? J. Cell Sci. 114 (Pt 16), 2903-2910.

Lee, S., Elenbaas, B., Levine, A., and Griffith, J. (1995). p53 and its 14 kDa C-terminal domain recognize primary DNA damage in the form of insertion/deletion mismatches. Cell 81 (7), 1013-1020. doi: 10.1016/s0092-8674(05)80006-6

Li, M., Brooks, C. L., Wu-Baer, F., Chen, D., Baer, R., and Gu, W. (2003). Monoversus polyubiquitination: differential control of $\mathrm{p} 53$ fate by Mdm2. Science 302 (5652), 1972-1975. doi: 10.1126/science.1091362

Lin, J., Chen, J., Elenbaas, B., and Levine, A. J. (1994). Several hydrophobic amino acids in the p53 amino-terminal domain are required for transcriptional activation, binding to $\mathrm{mdm}-2$ and the adenovirus $5 \mathrm{E} 1 \mathrm{~B} 55-\mathrm{kD}$ protein. Genes Dev. 8 (10), 1235-1246. doi: 10.1101/gad.8.10.1235

Linares, L. K., Kiernan, R., Triboulet, R., Chable-Bessia, C., Latreille, D., Cuvier, O., et al. (2007). Intrinsic ubiquitination activity of PCAF controls the stability of the oncoprotein Hdm2. Nat. Cell Biol. 9 (3), 331-338. doi: 10.1038/ncb1545

Liu, Y., and Kulesz-Martin, M. (2001). p53 protein at the hub of cellular DNA damage response pathways through sequence-specific and non-sequencespecific DNA binding. Carcinogenesis 22 (6), 851-860. doi: 10.1093/carcin/ 22.6 .851

Liu, T., Zhang, H., Xiong, J., Yi, S., Gu, L., and Zhou, M. (2015). Inhibition of MDM2 homodimerization by XIAP IRES stabilizes MDM2, influencing cancer cell survival. Mol. Cancer 14, 65. doi: 10.1186/s12943-015-0334-0

Liu, Y., Wang, X., Wang, G., Yang, Y., Yuan, Y., and Ouyang, L. (2019). The past, present and future of potential small-molecule drugs targeting p53-MDM2/ MDMX for cancer therapy. Eur. J. Med. Chem. 176, 92-104. doi: 10.1016/ j.ejmech.2019.05.018

Lohrum, M. A., Woods, D. B., Ludwig, R. L., Balint, E., and Vousden, K. H. (2001). C-terminal ubiquitination of p53 contributes to nuclear export. Mol. Cell Biol. 21 (24), 8521-8532. doi: 10.1128/MCB.21.24.8521-8532.2001

$\mathrm{Lu}, \mathrm{H}$., and Levine, A. J. (1995). Human TAFII31 protein is a transcriptional coactivator of the p53 protein. Proc. Natl. Acad. Sci. U. S. A 92 (11), 5154-5158. doi: $10.1073 /$ pnas.92.11.5154

Lu, X., Ma, O., Nguyen, T. A., Jones, S. N., Oren, M., and Donehower, L. A. (2007). The Wip1 Phosphatase acts as a gatekeeper in the p53-Mdm2 autoregulatory loop. Cancer Cell 12 (4), 342-354. doi: 10.1016/j.ccr.2007.08.033

Lukas, J., Gao, D. Q., Keshmeshian, M., Wen, W. H., Tsao-Wei, D., Rosenberg, S., et al. (2001). Alternative and aberrant messenger RNA splicing of the mdm2 oncogene in invasive breast cancer. Cancer Res. 61 (7), 3212-3219.

Lundgren, K., Montes, D. O. L. R., McNeill, Y. B., Emerick, E. P., Spencer, B., Barfield, C. R., et al. (1997). Targeted expression of MDM2 uncouples S phase from mitosis and inhibits mammary gland development independent of p53. Genes Dev. 11 (6), 714-725. doi: 10.1101/gad.11.6.714

Lushnikova, T., Bouska, A., Odvody, J., Dupont, W. D., and Eischen, C. M. (2011). Aging mice have increased chromosome instability that is exacerbated by elevated Mdm2 expression. Oncogene 30 (46), 4622-4631. doi: 10.1038/ onc.2011.172

Maglott, A., Bartik, P., Cosgun, S., Klotz, P., Ronde, P., Fuhrmann, G., et al. (2006). The small alpha5betal integrin antagonist, SJ749, reduces proliferation and clonogenicity of human astrocytoma cells. Cancer Res. 66 (12), 6002-6007. doi: 10.1158/0008-5472.CAN-05-4105

Maltzman, W., and Czyzyk, L. (1984). UV irradiation stimulates levels of p53 cellular tumor antigen in nontransformed mouse cells. Mol. Cell Biol. 4 (9), 1689-1694. doi: 10.1128/mcb.4.9.1689

Mann, B. S., Johnson, J. R., Cohen, M. H., Justice, R., and Pazdur, R. (2007). FDA approval summary: vorinostat for treatment of advanced primary cutaneous T-cell lymphoma. Oncologist 12 (10), 1247-1252. doi: 10.1634/theoncologist.12-10-1247
Mas-Moruno, C., Rechenmacher, F., and Kessler, H. (2010). Cilengitide: the first anti-angiogenic small molecule drug candidate design, synthesis and clinical evaluation. Anticancer Agents Med. Chem. 10 (10), 753-768. doi: 10.2174/ 187152010794728639

Matsumoto, R., Tada, M., Nozaki, M., Zhang, C. L., Sawamura, Y., and Abe, H. (1998). Short alternative splice transcripts of the $\mathrm{mdm} 2$ oncogene correlate to malignancy in human astrocytic neoplasms. Cancer Res. 58 (4), 609-613.

Maya, R., Balass, M., Kim, S. T., Shkedy, D., Leal, J. F., Shifman, O., et al. (2001). ATM-dependent phosphorylation of $\mathrm{Mdm} 2$ on serine 395: role in p53 activation by DNA damage. Genes Dev. 15 (9), 1067-1077. doi: 10.1101/ gad.886901

Mayo, L. D., and Donner, D. B. (2001). A phosphatidylinositol 3-kinase/Akt pathway promotes translocation of $\mathrm{Mdm} 2$ from the cytoplasm to the nucleus. Proc. Natl. Acad. Sci. U. S. A 98 (20), 11598-11603. doi: 10.1073/ pnas. 181181198

Mayo, L. D., and Donner, D. B. (2002). The PTEN, Mdm2, p53 tumor suppressoroncoprotein network. Trends Biochem. Sci. 27 (9), 462-467. doi: 10.1016/ s0968-0004(02)02166-7

Mayo, L. D., Turchi, J. J., and Berberich, S. J. (1997). Mdm-2 phosphorylation by DNA-dependent protein kinase prevents interaction with p53. Cancer Res. 57 (22), 5013-5016.

Mayo, L. D., Dixon, J. E., Durden, D. L., Tonks, N. K., and Donner, D. B. (2002). PTEN protects $\mathrm{p} 53$ from $\mathrm{Mdm} 2$ and sensitizes cancer cells to chemotherapy. J. Biol. Chem. 277 (7), 5484-5489. doi: 10.1074/jbc.M108302200

McCormack, E., Haaland, I., Venas, G., Forthun, R. B., Huseby, S., Gausdal, G., et al. (2012). Synergistic induction of p53 mediated apoptosis by valproic acid and nutlin-3 in acute myeloid leukemia. Leukemia 26 (5), 910-917. doi: 10.1038/leu.2011.315

McCoy, M. A., Gesell, J. J., Senior, M. M., and Wyss, D. F. (2003). Flexible lid to the p53-binding domain of human Mdm2: implications for p53 regulation. Proc. Natl. Acad. Sci. U. S. A 100 (4), 1645-1648. doi: 10.1073/pnas.0334477100

Meek, D. W., and Hupp, T. R. (2010). The regulation of MDM2 by multisite phosphorylation-opportunities for molecular-based intervention to target tumours? Semin. Cancer Biol. 20 (1), 19-28. doi: 10.1016/j.semcancer. 2009.10.005

Meek, D. W., and Knippschild, U. (2003). Posttranslational modification of MDM2. Mol. Cancer Res. 1 (14), 1017-1026.

Mendrysa, S. M., McElwee, M. K., Michalowski, J., O’Leary, K. A., Young, K. M., and Perry, M. E. (2003). mdm2 Is critical for inhibition of p53 during lymphopoiesis and the response to ionizing irradiation. Mol. Cell Biol. 23 (2), 462-472. doi: 10.1128/mcb.23.2.462-473.2003

Merlino, F., Daniele, S., La Pietra, V., Di Maro, S., Di Leva, F. S., Brancaccio, D., et al. (2018). Simultaneous Targeting of RGD-Integrins and Dual Murine Double Minute Proteins in Glioblastoma Multiforme. J. Med. Chem. 61 (11), 4791-4809. doi: 10.1021/acs.jmedchem.8b00004

Minsky, N., and Oren, M. (2004). The RING domain of Mdm2 mediates histone ubiquitylation and transcriptional repression. Mol. Cell 16 (4), 631-639. doi: 10.1016/j.molcel.2004.10.016

Mirzayans, R., Enns, L., Dietrich, K., Barley, R. D., and Paterson, M. C. (1996). Faulty DNA polymerase delta/epsilon-mediated excision repair in response to gamma radiation or ultraviolet light in $\mathrm{p} 53$-deficient fibroblast strains from affected members of a cancer-prone family with Li-Fraumeni syndrome. Carcinogenesis 17 (4), 691-698. doi: 10.1093/carcin/17.4.691

Mizutani, Y., Nakanishi, H., Li, Y. N., Matsubara, H., Yamamoto, K., Sato, N., et al. (2007). Overexpression of XIAP expression in renal cell carcinoma predicts a worse prognosis. Int. J. Oncol. 30 (4), 919-925. doi: 10.3892/ijo.30.4.919

Mladenov, E., Magin, S., Soni, A., and Iliakis, G. (2016). DNA double-strand-break repair in higher eukaryotes and its role in genomic instability and cancer: Cell cycle and proliferation-dependent regulation. Semin. Cancer Biol. 37-38, 5164. doi: 10.1016/j.semcancer.2016.03.003

Momand, J., Zambetti, G. P., Olson, D. C., George, D., and Levine, A. J. (1992). The mdm-2 oncogene product forms a complex with the $\mathrm{p} 53$ protein and inhibits p53-mediated transactivation. Cell 69 (7), 1237-1245. doi: 10.1016/ 0092-8674(92)90644-r

Montes, D. O. L. R., Wagner, D. S., and Lozano, G. (1995). Rescue of early embryonic lethality in $\mathrm{mdm} 2$-deficient mice by deletion of p53. Nature 378 (6553), 203-206. doi: 10.1038/378203a0 
Montesinos, P., Beckermann, B. M., Catalani, O., Esteve, J., Gamel, K., Konopleva, M. Y., et al. (2020). MIRROS: a randomized, placebo-controlled, Phase III trial of cytarabine +/- idasanutlin in relapsed or refractory acute myeloid leukemia. Future Oncol. 16 (13), 807-815. doi: 10.2217/fon-2020-0044

Morgan, W. F., Corcoran, J., Hartmann, A., Kaplan, M. I., Limoli, C. L., and Ponnaiya, B. (1998). DNA double-strand breaks, chromosomal rearrangements, and genomic instability. Mutat. Res. 404 (1-2), 125-128. doi: 10.1016/s0027-5107(98)00104-3

Ogawara, Y., Kishishita, S., Obata, T., Isazawa, Y., Suzuki, T., Tanaka, K., et al. (2002). Akt enhances Mdm2-mediated ubiquitination and degradation of p53. J. Biol. Chem. 277 (24), 21843-21850. doi: 10.1074/jbc.M109745200

Okamoto, K., Li, H., Jensen, M. R., Zhang, T., Taya, Y., Thorgeirsson, S. S., et al. (2002). Cyclin G recruits PP2A to dephosphorylate Mdm2. Mol. Cell 9 (4), 761-771. doi: 10.1016/s1097-2765(02)00504-x

Okoro, D. R., Arva, N., Gao, C., Polotskaia, A., Puente, C., Rosso, M., et al. (2013). Endogenous human MDM2-C is highly expressed in human cancers and functions as a p53-independent growth activator. PloS One 8 (10), e77643. doi: 10.1371/journal.pone. 0077643

Oliner, J. D., Kinzler, K. W., Meltzer, P. S., George, D. L., and Vogelstein, B. (1992). Amplification of a gene encoding a $\mathrm{p} 53$-associated protein in human sarcomas. Nature 358 (6381), 80-83. doi: 10.1038/358080a0

Oliner, J. D., Pietenpol, J. A., Thiagalingam, S., Gyuris, J., Kinzler, K. W., and Vogelstein, B. (1993). Oncoprotein MDM2 conceals the activation domain of tumour suppressor p53. Nature 362 (6423), 857-860. doi: 10.1038/362857a0

Pahl, H. L. (1999). Activators and target genes of Rel/NF-kappaB transcription factors. Oncogene 18 (49), 6853-6866. doi: 10.1038/sj.onc.1203239

Patnaik, A., Tolcher, A., Beeram, M., Nemunaitis, J., Weiss, G. J., Bhalla, K., et al. (2015). Clinical pharmacology characterization of RG7112, an MDM2 antagonist, in patients with advanced solid tumors. Cancer Chemother. Pharmacol. 76 (3), 587-595. doi: 10.1007/s00280-015-2830-8

Paull, T. T., and Gellert, M. (1999). Nbs1 potentiates ATP-driven DNA unwinding and endonuclease cleavage by the Mre11/Rad50 complex. Genes Dev. 13 (10), 1276-1288. doi: 10.1101/gad.13.10.1276

Pichiorri, F., Suh, S. S., Rocci, A., De Luca, L., Taccioli, C., Santhanam, R., et al. (2010). Downregulation of p53-inducible microRNAs 192, 194, and 215 impairs the p53/MDM2 autoregulatory loop in multiple myeloma development. Cancer Cell 18 (4), 367-381. doi: 10.1016/j.ccr.2010.09.005

Primo, L., and Teixeira, L. K. (2019). DNA replication stress: oncogenes in the spotlight. Genet. Mol. Biol. 43 (1 suppl 1), e20190138. doi: 10.1590/16784685GMB-2019-0138

Purdie, C. A., Harrison, D. J., Peter, A., Dobbie, L., White, S., Howie, S. E., et al. (1994). Tumour incidence, spectrum and ploidy in mice with a large deletion in the p53 gene. Oncogene 9 (2), 603-609.

Ranaweera, R. S., and Yang, X. (2013). Auto-ubiquitination of Mdm2 enhances its substrate ubiquitin ligase activity. J. Biol. Chem. 288 (26), 18939-18946. doi: 10.1074/jbc.M113.454470

Ravandi, F., Gojo, I., Patnaik, M. M., Minden, M. D., Kantarjian, H., JohnsonLevonas, A. O., et al. (2016). A phase I trial of the human double minute 2 inhibitor (MK-8242) in patients with refractory/recurrent acute myelogenous leukemia (AML). Leuk. Res. 48, 92-100. doi: 10.1016/j.leukres.2016.07.004

Reis, B., Jukofsky, L., Chen, G., Martinelli, G., Zhong, H., So, W. V., et al. (2016). Acute myeloid leukemia patients' clinical response to idasanutlin (RG7388) is associated with pre-treatment MDM2 protein expression in leukemic blasts. Haematologica 101 (5), e185-e188. doi: 10.3324/haematol.2015.139717

Rosso, M., Okoro, D. E., and Bargonetti, J. (2014). Splice variants of MDM2 in oncogenesis. Subcell. Biochem. 85, 247-261. doi: 10.1007/978-94-017-9211-0_14

Sanchez-Aguilera, A., Garcia, J. F., Sanchez-Beato, M., and Piris, M. A. (2006). Hodgkin's lymphoma cells express alternatively spliced forms of HDM2 with multiple effects on cell cycle control. Oncogene 25 (18), 2565-2574. doi: 10.1038/sj.onc. 1209282

Seipel, K., Marques, M., Sidler, C., Mueller, B. U., and Pabst, T. (2018). MDM2and FLT3-inhibitors in the treatment of FLT3-ITD acute myeloid leukemia, specificity and efficacy of NVP-HDM201 and midostaurin. Haematologica 103 (11), 1862-1872. doi: 10.3324/haematol.2018.191650

Senturk, E., and Manfredi, J. J. (2012). Mdm2 and tumorigenesis: evolving theories and unsolved mysteries. Genes Cancer 3 (3-4), 192-198. doi: 10.1177/ 1947601912457368
Shafman, T., Khanna, K. K., Kedar, P., Spring, K., Kozlov, S., Yen, T., et al. (1997). Interaction between ATM protein and c-Abl in response to DNA damage. Nature 387 (6632), 520-523. doi: 10.1038/387520a0

Shieh, S. Y., Ikeda, M., Taya, Y., and Prives, C. (1997). DNA damage-induced phosphorylation of p53 alleviates inhibition by MDM2. Cell 91 (3), 325-334. doi: $10.1016 / \mathrm{s} 0092-8674(00) 80416-\mathrm{x}$

Shirai, Y., Shiba, H., Iwase, R., Haruki, K., Fujiwara, Y., Furukawa, K., et al. (2016). Dual inhibition of nuclear factor kappa-B and Mdm2 enhance the antitumor effect of radiation therapy for pancreatic cancer. Cancer Lett. 370 (2), 177-184. doi: 10.1016/j.canlet.2015.10.034

Sigalas, I., Calvert, A. H., Anderson, J. J., Neal, D. E., and Lunec, J. (1996). Alternatively spliced $\mathrm{mdm} 2$ transcripts with loss of p53 binding domain sequences: transforming ability and frequent detection in human cancer. Nat. Med. 2 (8), 912-917. doi: 10.1038/nm0896-912

Sionov, R. V., Coen, S., Goldberg, Z., Berger, M., Bercovich, B., Ben-Neriah, Y., et al. (2001). c-Abl regulates p53 levels under normal and stress conditions by preventing its nuclear export and ubiquitination. Mol. Cell Biol. 21 (17), 58695878. doi: $10.1128 / \mathrm{mcb} .21 .17 .5869-5878.2001$

Skalniak, L., Kocik, J., Polak, J., Skalniak, A., Rak, M., Wolnicka-Glubisz, A., et al. (2018). Prolonged Idasanutlin (RG7388) Treatment Leads to the Generation of p53-Mutated Cells. Cancers (Basel) 10 (11), 396. doi: 10.3390/cancers10110396

Smith, M. L., Chen, I. T., Zhan, Q., O'Connor, P. M., and Fornace, A. J. (1995). Involvement of the $\mathrm{p} 53$ tumor suppressor in repair of u.v.-type DNA damage. Oncogene 10 (6), 1053-1059.

Soutoglou, E., and Misteli, T. (2010). Activation of the cellular DNA damage response in the absence of DNA lesions (vol 320, pg 1507, 2008). Science 327 (5968), 959. doi: 10.1126/science.1159051

Stommel, J. M., and Wahl, G. M. (2004). Accelerated MDM2 auto-degradation induced by DNA-damage kinases is required for p53 activation. EMBO J. 23 (7), 1547-1556. doi: 10.1038/sj.emboj.7600145

Stommel, J. M., and Wahl, G. M. (2005). A new twist in the feedback loop: stressactivated MDM2 destabilization is required for p53 activation. Cell Cycle 4 (3), 411-417. doi: 10.4161/cc.4.3.1522

Stracker, T. H., Theunissen, J. W., Morales, M., and Petrini, J. H. (2004). The Mre11 complex and the metabolism of chromosome breaks: the importance of communicating and holding things together. DNA Repair (Amst) 3 (8-9), 845854. doi: 10.1016/j.dnarep.2004.03.014

Sui, G., Affar, E. B., Shi, Y., Brignone, C., Wall, N. R., Yin, P., et al. (2004). Yin Yang 1 is a negative regulator of p53. Cell 117 (7), 859-872. doi: 10.1016/ j.cell.2004.06.004

Sullivan, K. D., Galbraith, M. D., Andrysik, Z., and Espinosa, J. M. (2018). Mechanisms of transcriptional regulation by p53. Cell Death Differ. 25 (1), 133-143. doi: 10.1038/cdd.2017.174

Sun, D., Li, Z., Rew, Y., Gribble, M., Bartberger, M. D., Beck, H. P., et al. (2014). Discovery of AMG 232, a potent, selective, and orally bioavailable MDM2-p53 inhibitor in clinical development. J. Med. Chem. 57 (4), 1454-1472. doi: $10.1021 / \mathrm{jm} 401753$ e

Tait, S. W., and Green, D. R. (2010). Mitochondria and cell death: outer membrane permeabilization and beyond. Nat. Rev. Mol. Cell Biol. 11 (9), 621-632. doi: $10.1038 / \mathrm{nrm} 2952$

Takahashi, Y., Kitadai, Y., Bucana, C. D., Cleary, K. R., and Ellis, L. M. (1995). Expression of vascular endothelial growth factor and its receptor, KDR, correlates with vascularity, metastasis, and proliferation of human colon cancer. Cancer Res. 55 (18), 3964-3968.

Tamm, I., Richter, S., Oltersdorf, D., Creutzig, U., Harbott, J., Scholz, F., et al. (2004). High expression levels of $x$-linked inhibitor of apoptosis protein and survivin correlate with poor overall survival in childhood de novo acute myeloid leukemia. Clin. Cancer Res. 10 (11), 3737-3744. doi: 10.1158/10780432.CCR-03-0642

Tan, J., Cang, S., Ma, Y., Petrillo, R. L., and Liu, D. (2010). Novel histone deacetylase inhibitors in clinical trials as anti-cancer agents. J. Hematol. Oncol. 3, 5. doi: 10.1186/1756-8722-3-5

Tang, Y., Zhao, W., Chen, Y., Zhao, Y., and Gu, W. (2008). Acetylation is indispensable for p53 activation. Cell 133 (4), 612-626. doi: 10.1016/ j.cell.2008.03.025

Teveroni, E., Luca, R., Pellegrino, M., Ciolli, G., Pontecorvi, A., and Moretti, F. (2016). Peptides and peptidomimetics in the p53/MDM2/MDM4 circuitry - a 
patent review. Expert Opin. Ther. Pat. 26 (12), 1417-1429. doi: 10.1080/ 13543776.2017.1233179

Thut, C. J., Chen, J. L., Klemm, R., and Tjian, R. (1995). p53 transcriptional activation mediated by coactivators TAFII40 and TAFII60. Science 267 (5194), 100-104. doi: 10.1126/science.7809597

Thut, C. J., Goodrich, J. A., and Tjian, R. (1997). Repression of p53-mediated transcription by MDM2: a dual mechanism. Genes Dev. 11 (15), 1974-1986. doi: 10.1101/gad.11.15.1974

Tolcher, A. W., Fang, D. D., Li, Y., Tang, Y., Ji, J., Wang, H., et al. (2019). 2OA phase Ib/II study of APG-115 in combination with pembrolizumab in patients with unresectable or metastatic melanomas or advanced solid tumors. Ann. Oncol. 30, 1. doi: 10.1093/annonc/mdz027

Valentin-Vega, Y. A., Barboza, J. A., Chau, G. P., El-Naggar, A. K., and Lozano, G. (2007). High levels of the p53 inhibitor MDM4 in head and neck squamous carcinomas. Hum. Pathol. 38 (10), 1553-1562. doi: 10.1016/j.humpath.2007.03.005

Vanhaesebroeck, B., and Alessi, D. R. (2000). The PI3K-PDK1 connection: more than just a road to PKB. Biochem. J. 346 Pt 3, 561-576. doi: 10.1042/02646021:3460561

Vassilev, L. T., Vu, B. T., Graves, B., Carvajal, D., Podlaski, F., Filipovic, Z., et al. (2004). In vivo activation of the p53 pathway by small-molecule antagonists of MDM2. Science 303 (5659), 844-848. doi: 10.1126/science.1092472

Vazquez, A., Bond, E. E., Levine, A. J., and Bond, G. L. (2008). The genetics of the p53 pathway, apoptosis and cancer therapy. Nat. Rev. Drug Discovery 7 (12), 979-987. doi: $10.1038 / \mathrm{nrd} 2656$

Verreault, M., Schmitt, C., Goldwirt, L., Pelton, K., Haidar, S., Levasseur, C., et al. (2016). Preclinical Efficacy of the MDM2 Inhibitor RG7112 in MDM2Amplified and TP53 Wild-type Glioblastomas. Clin. Cancer Res. 22 (5), 1185-1196. doi: 10.1158/1078-0432.CCR-15-1015

Volk, E. L., Fan, L., Schuster, K., Rehg, J. E., and Harris, L. C. (2009). The MDM2-a splice variant of MDM2 alters transformation in vitro and the tumor spectrum in both Arf- and p53-null models of tumorigenesis. Mol. Cancer Res. 7 (6), 863-869. doi: 10.1158/1541-7786.MCR-08-0418

Vu, B., Wovkulich, P., Pizzolato, G., Lovey, A., Ding, Q., Jiang, N., et al. (2013). Discovery of RG7112: A Small-Molecule MDM2 Inhibitor in Clinical Development. ACS Med. Chem. Lett. 4 (5), 466-469. doi: 10.1021/ml4000657

Wade, M., Li, Y. C., and Wahl, G. M. (2013). MDM2, MDMX and p53 in oncogenesis and cancer therapy. Nat. Rev. Cancer 13 (2), 83-96. doi: 10.1038/nrc3430

Wagner, A. J., Banerji, U., Mahipal, A., Somaiah, N., Hirsch, H., Fancourt, C., et al. (2017). Phase I Trial of the Human Double Minute 2 Inhibitor MK-8242 in Patients With Advanced Solid Tumors. J. Clin. Oncol. 35 (12), 1304-1311. doi: 10.1200/JCO.2016.70.7117

Wang, P., Lushnikova, T., Odvody, J., Greiner, T. C., Jones, S. N., and Eischen, C. M. (2008). Elevated Mdm2 expression induces chromosomal instability and confers a survival and growth advantage to B cells. Oncogene 27 (11), 15901598. doi: $10.1038 /$ sj.onc. 1210788

Wang, S. P., Wang, W. L., Chang, Y. L., Wu, C. T., Chao, Y. C., Kao, S. H., et al. (2009). p53 controls cancer cell invasion by inducing the MDM2-mediated degradation of Slug. Nat. Cell Biol. 11 (6), 694-704. doi: 10.1038/ncb1875

Wang, S., Sun, W., Zhao, Y., McEachern, D., Meaux, I., Barriere, C., et al. (2014). SAR405838: an optimized inhibitor of MDM2-p53 interaction that induces complete and durable tumor regression. Cancer Res. 74 (20), 5855-5865. doi: 10.1158/0008-5472.CAN-14-0799

Weber, J. D., Taylor, L. J., Roussel, M. F., Sherr, C. J., and Bar-Sagi, D. (1999). Nucleolar Arf sequesters Mdm2 and activates p53. Nat. Cell Biol. 1 (1), 20-26. doi: $10.1038 / 8991$

Wei, X., Yu, Z. K., Ramalingam, A., Grossman, S. R., Yu, J. H., Bloch, D. B., et al. (2003). Physical and functional interactions between PML and MDM2. J. Biol. Chem. 278 (31), 29288-29297. doi: 10.1074/jbc.M212215200

Welsch, M. E., Snyder, S. A., and Stockwell, B. R. (2010). Privileged scaffolds for library design and drug discovery. Curr. Opin. Chem. Biol. 14 (3), 347-361. doi: $10.1016 /$ j.cbpa.2010.02.018
Wienken, M., Moll, U. M., and Dobbelstein, M. (2017). Mdm2 as a chromatin modifier. J. Mol. Cell Biol. 9 (1), 74-80. doi: 10.1093/jmcb/mjw046

Williams, A. B., and Schumacher, B. (2016). p53 in the DNA-Damage-Repair Process. Cold Spring Harb. Perspect. Med. 6 (5). doi: 10.1101/cshperspect. a026070

Williams, R. S., Williams, J. S., and Tainer, J. A. (2007). Mre11-Rad50-Nbs1 is a keystone complex connecting DNA repair machinery, double-strand break signaling, and the chromatin template. Biochem. Cell Biol. 85 (4), 509-520. doi: 10.1139/O07-069

Xiao, Z. X., Chen, J., Levine, A. J., Modjtahedi, N., Xing, J., Sellers, W. R., et al. (1995). Interaction between the retinoblastoma protein and the oncoprotein MDM2. Nature 375 (6533), 694-698. doi: 10.1038/375694a0

Xirodimas, D. P., Saville, M. K., Bourdon, J. C., Hay, R. T., and Lane, D. P. (2004). Mdm2-mediated NEDD8 conjugation of p53 inhibits its transcriptional activity. Cell 118 (1), 83-97. doi: 10.1016/j.cell.2004.06.016

Xu, W. S., Parmigiani, R. B., and Marks, P. A. (2007). Histone deacetylase inhibitors: molecular mechanisms of action. Oncogene 26 (37), 5541-5552. doi: 10.1038/sj.onc.1210620

Yang, J. Y., Zong, C. S., Xia, W., Wei, Y., Ali-Seyed, M., Li, Z., et al. (2006). MDM2 promotes cell motility and invasiveness by regulating E-cadherin degradation. Mol. Cell Biol. 26 (19), 7269-7282. doi: 10.1128/MCB.00172-06

Yang, J. Y., Zong, C. S., Xia, W., Yamaguchi, H., Ding, Q., Xie, X., et al. (2008). ERK promotes tumorigenesis by inhibiting FOXO3a via MDM2-mediated degradation. Nat. Cell Biol. 10 (2), 138-148. doi: 10.1038/ncb1676

Zauberman, A., Flusberg, D., Haupt, Y., Barak, Y., and Oren, M. (1995). A functional p53-responsive intronic promoter is contained within the human mdm2 gene. Nucleic Acids Res. 23 (14), 2584-2592. doi: 10.1093/nar/ 23.14.2584

Zhang, L., and Hill, R. P. (2004). Hypoxia enhances metastatic efficiency by upregulating Mdm2 in KHT cells and increasing resistance to apoptosis. Cancer Res. 64 (12), 4180-4189. doi: 10.1158/0008-5472.CAN-03-3038

Zhang, Y., Xiong, Y., and Yarbrough, W. G. (1998). ARF promotes MDM2 degradation and stabilizes p53: ARF-INK4a locus deletion impairs both the Rb and p53 tumor suppression pathways. Cell 92 (6), 725-734. doi: 10.1016/s00928674(00)81401-4

Zhou, B. P., Liao, Y., Xia, W., Zou, Y., Spohn, B., and Hung, M. C. (2001). HER-2/ neu induces p53 ubiquitination via Akt-mediated MDM2 phosphorylation. Nat. Cell Biol. 3 (11), 973-982. doi: 10.1038/ncb1101-973

Zhuang, C., Miao, Z., Wu, Y., Guo, Z., Li, J., Yao, J., et al. (2014). Double-edged swords as cancer therapeutics: novel, orally active, small molecules simultaneously inhibit p53-MDM2 interaction and the NF-kappaB pathway. J. Med. Chem. 57 (3), 567-577. doi: 10.1021/jm401800k

Zietz, C., Rossle, M., Haas, C., Sendelhofert, A., Hirschmann, A., Sturzl, M., et al. (1998). MDM-2 oncoprotein overexpression, p53 gene mutation, and VEGF up-regulation in angiosarcomas. Am. J. Pathol. 153 (5), 1425-1433. doi: $10.1016 / \mathrm{S} 0002-9440(10) 65729-\mathrm{X}$

Zindy, F., Eischen, C. M., Randle, D. H., Kamijo, T., Cleveland, J. L., Sherr, C. J., et al. (1998). Myc signaling via the ARF tumor suppressor regulates p53dependent apoptosis and immortalization. Genes Dev. 12 (15), 2424-2433. doi: 10.1101/gad.12.15.2424

Conflict of Interest: The authors declare that the research was conducted in the absence of any commercial or financial relationships that could be construed as a potential conflict of interest.

Copyright (c) $2020 \mathrm{Li}$, Peng, Lang and Xu. This is an open-access article distributed under the terms of the Creative Commons Attribution License (CC BY). The use, distribution or reproduction in other forums is permitted, provided the original author(s) and the copyright owner(s) are credited and that the original publication in this journal is cited, in accordance with accepted academic practice. No use, distribution or reproduction is permitted which does not comply with these terms. 